\title{
Photodissociation Dynamics of the Cyclohexyl Radical from the 3p Rydberg State at $248 \mathrm{~nm}$
}

Isaac A. Ramphal, ${ }^{\dagger, *}$ Mark Shapero, ${ }^{\dagger, \dagger}$ Daniel M. Neumark $*, \dagger, \ddagger$

†Chemical Sciences Division, Lawrence Berkeley National Laboratory, Berkeley, California 94720, USA

"Department of Chemistry, University of California, Berkeley, California 94720, USA

\begin{abstract}
The photodissociation of jet-cooled cyclohexyl was studied by exciting the radicals to their $3 p$ Rydberg state using $248 \mathrm{~nm}$ laser light and detecting photoproducts by photofragment translational spectroscopy. Both $\mathrm{H}$-atom loss and dissociation to heavy fragment pairs are observed. The H-atom loss channel exhibits a two-component translational energy distribution. The fast photoproduct component is attributed to impulsive cleavage directly from an excited state, likely the Rydberg $3 \mathrm{~s}$ state, forming cyclohexene. The slow component is due to statistical decomposition of hot cyclohexyl radicals that internally convert to the ground electronic state prior to H-atom loss. The fast and slow components are present in a $\sim 0.7: 1$ ratio, similar to findings in other alkyl radicals. Internal conversion to the ground state also leads to ring-opening followed by dissociation to 1-buten-4-yl + ethene in comparable yield to H-loss, with the $\mathrm{C}_{4} \mathrm{H}_{7}$ fragment containing enough internal energy to dissociate further to butadiene via $\mathrm{H}$-atom loss. A very minor ground-state $\mathrm{C}_{5} \mathrm{H}_{8}+\mathrm{CH}_{3}$ channel is observed, attributed predominantly to 1,3pentadiene formation. The ground-state branching ratios agree well with RRKM calculations, which also predict $\mathrm{C}_{4} \mathrm{H}_{6}+\mathrm{C}_{2} \mathrm{H}_{5}$ and $\mathrm{C}_{3} \mathrm{H}_{6}+\mathrm{C}_{3} \mathrm{H}_{5}$ channels with similar yield to $\mathrm{C}_{5} \mathrm{H}_{8}+\mathrm{CH}_{3}$. If these channels were active it was at levels too low to be observed.
\end{abstract}

\section{Introduction}

Alkanes comprise a large fraction of chemical species in hydrocarbon fuel mixes, including substantial amounts of cycloalkanes. ${ }^{1-2}$ Given their abundance, a detailed understanding of hydrocarbon combustion requires knowledge of possible decomposition pathways available to alkanes, in which alkyl radicals are crucially important. Alkanes emitted directly into the atmosphere by industrial activities are oxidized through an array of homogeneous and heterogeneous chemical transformations involving radicals. ${ }^{3-4}$ Alkyl radical photochemistry is also important to consider, both on earth and in other planetary atmospheres where hydrocarbons are abundant. ${ }^{5-6}$ In this paper, we investigate the photodissociation of cyclohexyl radicals at $248 \mathrm{~nm}$ to determine its primary photochemistry and dissociation mechanisms using photofragment translational spectroscopy.

Alkyl radical photochemistry is of fundamental interest ${ }^{7-9}$ and the electronic absorption spectra of alkyl radicals have previously been characterized. ${ }^{10}$ The lowest lying electronic excited states available to alkyl radicals are the $3 \mathrm{~s}$ and $3 \mathrm{p}_{z}$ (henceforth referred to as $3 \mathrm{p}$ ) Rydberg states. While there has been a great deal of historical interest in the photodissociation dynamics of methyl ${ }^{11-13}$ and ethyl ${ }^{14-17}$ radicals, larger alkyl radicals have only been addressed more recently. Furthermore, to date there are no published works on the ultraviolet photodissociation dynamics of a cycloalkyl radical.

Previous photodissociation studies from the $3 \mathrm{~s}$ and 3p Rydberg states of ethyl by Zhang, Fischer, Bañares and co-workers detected $\mathrm{H}$ atoms ejected with a bimodal kinetic energy distribution. ${ }^{14-17}$ The 'fast' $\mathrm{H}$ atoms result from direct dissociation from the excited electronic state, while the 'slow' population is attributed to statistical dissociation following internal conversion to the ground state. The observation of angular distributions that are anisotropic for the fast $\mathrm{H}$ atoms and isotropic for the slow $\mathrm{H}$ atoms supports these mechanisms. These fast and slow dissociation channels occur in a roughly $0.4: 1$ ratio depending on the initial and final states of ethyl used in the experiment. For ethyl excited to the $3 \mathrm{~s}$ state, the fast dissociation channel has a dissociation time constant of $\sim 300 \mathrm{fs}$, while for the slow channel it is $\sim 6-7 \mathrm{ps}^{18}$ 
Photodissociation of $n$-propyl, $i$-propyl, $n$-butyl, $s$-butyl, $t$-butyl, and 1-pentyl radicals have all produced data that are consistent with the same H-loss mechanisms outlined above for the ethyl radical ${ }^{8,19-21}$ For all of these radicals as for ethyl, the fast and slow $\mathrm{H}$-loss channels occur in a 0.2-0.7:1 ratio, assuming $\mathrm{H}$ atoms with different speeds are detected with equal efficiency. Similar experiments on cyclohexyl radical were carried out by Zhang and co-workers but have not been published. ${ }^{22}$ Fast $\mathrm{H}$-atom photofragments were observed, but slow $\mathrm{H}$ atoms were not seen despite this being the dominant $\mathrm{H}$-loss channel for all other alkyl radicals studied to date. In addition, for most studies on the photodissociation dynamics of alkyl radicals, the detection scheme is only sensitive to $\mathrm{H}$ atoms, and cannot yield direct information about potential competing dissociation pathways. A notable exception is photodissociation of $t$-butyl radical excited to the $3 p$ state, which produced $\mathrm{CH}_{3}+$ dimethylcarbene in roughly equal amounts to $\mathrm{H}+2$-methylpropene ( $i$ butene). ${ }^{23}$

Numerous studies concerning the thermal decomposition of cyclohexyl radical have appeared in the context of understanding the decomposition pathways of cyclohexane during combustion. ${ }^{24-28}$ Of particular interest is the competition between direct $\mathrm{H}$-atom loss adjacent to the radical site to form cyclohexene and $\mathrm{C}-\mathrm{C} \beta$ scission yielding the radical-terminated linear alkene 1-hexen-6-yl:

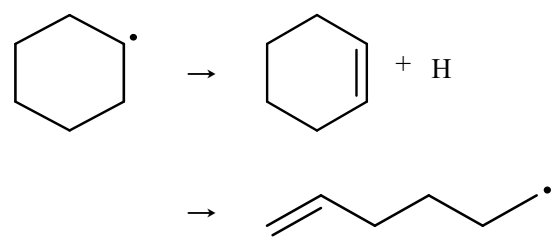

Shock tube and flame studies on cyclohexane find data consistent with a preponderance for ring-opening, with the direct $\mathrm{H}$-loss to ring-opening branching ratio $~ 0.3-0.9: 1$ depending upon experimental conditions. ${ }^{24-25}$ Low-pressure (30 Torr) pyrolysis of cyclohexane in a flow reactor, probed with VUV photoionization mass spectrometry, found a similar 0.25:1 ratio for these reactions. ${ }^{26}$ Comparably lowpressure chemical activation studies also yielded cyclopentylmethyl radical, formed either by ringcontraction of cyclohexyl through a tight transition state, or stepwise by the recyclization of 1-hexen-6yl. ${ }^{27-28}$ However, pyrolysis of cyclohexyl radicals under unimolecular conditions produced no evidence for cyclopentylmethyl in photoionization spectra. ${ }^{29}$

While all the $\mathrm{C}_{6} \mathrm{H}_{11}$ isomers described above can decompose by H-atom loss, ring-opening to 1-hexen-6-yl facilitates many additional dissociation channels. Various experimental and theoretical studies on decomposition of both cyclohexane and 1-hexene have implicated 1-hexen-6-yl in the following: ${ }^{24-26,29-36}$

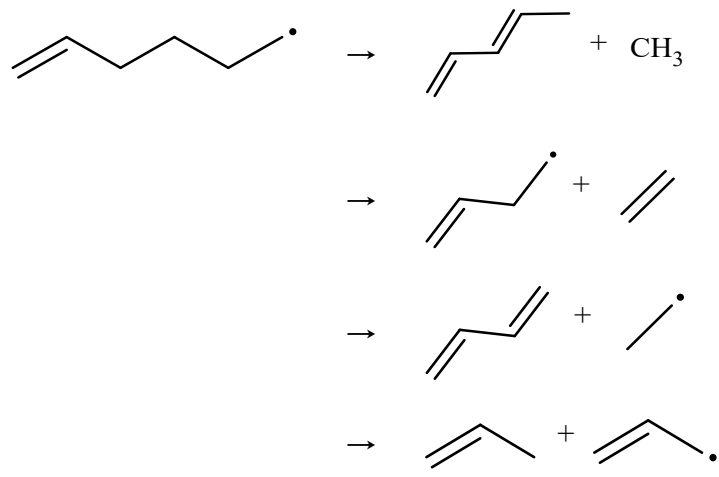

Aside from the 1-buten-4-yl + ethene channel, all of the above reactions require further isomerization to other $\mathrm{C}_{6} \mathrm{H}_{11}$ species before dissociation can occur. Goldsmith et al. ${ }^{33}$ and Gong et al. ${ }^{34}$ in particular provide a detailed picture of many isomerization and dissociation reactions on the $\mathrm{C}_{6} \mathrm{H}_{11}$ potential energy surface. The relative energies of these product channels compared to cyclohexyl are shown in Table 1. 
Table 1. Asymptotic energies for cyclohexyl dissociation channels. All channels except $\mathrm{H}+$ cyclohexene require ring-opening to proceed. Energies are reported in units of $\mathrm{kcal} / \mathrm{mol}$ and taken from Ref. 34, except for $\mathrm{H}+1,5$-hexadiene which was calculated here.

\begin{tabular}{lc} 
Product Channel & $\boldsymbol{\Delta H}(\mathbf{0}$ K) \\
\hline $\mathrm{H}+$ cyclohexene & 31.3 \\
$\mathrm{H}+1,5$-hexadiene & 55.7 \\
$\mathrm{C}_{5} \mathrm{H}_{8}+\mathrm{CH}_{3}$ & 34.6 \\
$\mathrm{C}_{4} \mathrm{H}_{7}+\mathrm{C}_{2} \mathrm{H}_{4}$ & 44.1 \\
$\mathrm{C}_{4} \mathrm{H}_{6}+\mathrm{C}_{2} \mathrm{H}_{5}$ & 37.2 \\
$\mathrm{C}_{3} \mathrm{H}_{6}+\mathrm{C}_{3} \mathrm{H}_{5}$ & 27.9
\end{tabular}

Cyclohexyl radicals adopt the boat conformer equilibrium geometry with $\mathrm{C}_{\mathrm{s}}$ symmetry, and a $5.6 \mathrm{kcal} / \mathrm{mol}$ isomerization barrier separating the two boat conformers. ${ }^{37}$ The most stable conformation has a nearly planar geometry about the radical site, with the $\alpha$-hydrogen in the equatorial position. Electron impact has determined the ionization potential to be $7.66 \mathrm{eV} .{ }^{38}$ The absorption spectrum of cyclohexyl radicals shows a broad feature around $250 \mathrm{~nm}$ corresponding to the $3 \mathrm{p}$ Rydberg excited state. ${ }^{10,39}$

Given that most photodissociation studies on alkyl radicals rely heavily on H-atom-specific detection schemes, and the lack of studies concerning the photodissociation of cycloalkyl radicals altogether, this work seeks to characterize the photochemistry of cyclohexyl radicals excited at $248 \mathrm{~nm}$ to the $3 p$ Rydberg state. The universal detection scheme utilized herein for photofragment translational spectroscopy is capable of detecting all possible photoproducts. In addition to $\mathrm{H}$-atom loss, we find evidence for $\mathrm{C}_{6} \mathrm{H}_{10}+$ $\mathrm{H}, \mathrm{C}_{5} \mathrm{H}_{8}+\mathrm{CH}_{3}$, and $\mathrm{C}_{4} \mathrm{H}_{7}+\mathrm{C}_{2} \mathrm{H}_{4}$ dissociation channels, and no evidence of the $\mathrm{C}_{5} \mathrm{H}_{4}+\mathrm{C}_{2} \mathrm{H}_{5}$ or $\mathrm{C}_{3} \mathrm{H}_{6}+$ $\mathrm{C}_{3} \mathrm{H}_{5}$ channels. Comparison to previous work on the ethyl radical suggests that the initially prepared $3 p$ state converts to the $3 \mathrm{~s}$ Rydberg state, followed by passage through a conical intersection with the ground state. ${ }^{17}$ Traversing the conical intersection either liberates $\mathrm{H}$ atoms directly or results in hot ground state cyclohexyl that dissociates according to statistical energy partitioning. The $\mathrm{C}_{4} \mathrm{H}_{7}$ fragment is formed with enough internal energy to further decompose, proceeding almost exclusively to butadiene $+\mathrm{H}$.

\section{Experimental}

\section{Precursor synthesis and characterization}

Flash vacuum pyrolysis of alkyl nitrites yields alkyl radicals via sequential loss of $\mathrm{NO}$ and $\mathrm{CH}_{2} \mathrm{O}$ (Scheme 1). Cyclohexylmethyl nitrite was synthesized from cyclohexanemethanol by reaction of the alcohol with HONO, and collected as a viscous, pale yellow liquid. ${ }^{40}$ The production and purity of cyclohexylmethyl nitrite was verified using NMR spectroscopy $\left(400 \mathrm{MHz}, \mathrm{C}_{6} \mathrm{D}_{6},\left(\mathrm{CH}_{3}\right)_{4} \mathrm{Si}\right),{ }^{1} \mathrm{H}-\mathrm{NMR}$ : $\delta$ (ppm) $0.68(2 \mathrm{H}, \mathrm{q}$, $o$-CH axial), 0.97 (3H, m, $m, p$ - $\mathrm{CH}$ axial), $1.33(1 \mathrm{H}, \mathrm{m}, \alpha-\mathrm{CH}), 1.47(5 \mathrm{H}, \mathrm{m}, o, m, p-\mathrm{CH}$ equatorial), 4.12 $\left(2 \mathrm{H}, \mathrm{s},-\mathrm{CH}_{2} \mathrm{ONO}\right)$, and ${ }^{13} \mathrm{C}-\mathrm{NMR}: \delta(\mathrm{ppm}) 25.5\left(m-\mathrm{CH}_{2}\right), 26.1\left(p-\mathrm{CH}_{2}\right), 29.3\left(o-\mathrm{CH}_{2}\right), 37.2(\alpha-\mathrm{CH}), 73.2$ $\left(-\mathrm{CH}_{2} \mathrm{ONO}\right)$. The chemical shifts, splitting patterns, and integrated peak intensities were consistent with expectations for cyclohexylmethyl nitrite, and the ${ }^{1} \mathrm{H}-\mathrm{NMR}$ peak at $1.58 \mathrm{ppm}$ due to the alcohol group is absent from the product spectrum. Cyclohexylmethyl nitrite was stored at $\leq 5{ }^{\circ} \mathrm{C}$ and away from light to minimize decomposition.

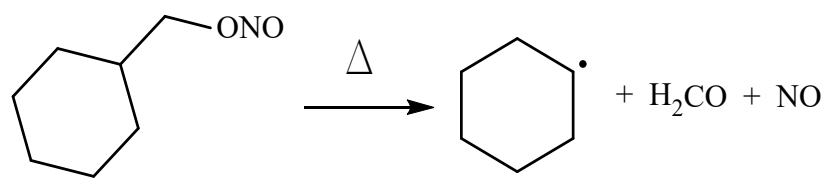

Scheme 1. Generation of cyclohexyl radicals by pyrolysis of cyclohexylmethyl nitrite. This two-step reaction proceeds via NO-loss followed by liberation of formaldehyde to afford cyclohexyl. 


\section{Photodissociation experiments}

Photodissociation of cyclohexyl was studied using a modified crossed molecular beam instrument with a fixed source and a rotatable detector. ${ }^{41-42}$ Cyclohexylmethyl nitrite was entrained in $\sim 900$ Torr of a carrier gas mix consisting of $10 \% \mathrm{~N}_{2}$ in He bubbled through an ice-water cooled reservoir of the nitrite, resulting in a $\sim 0.5 \%$ nitrite beam. Supersonic expansion through a piezoelectric pulsed valve introduced the molecular beam directly into a resistively heated $\mathrm{SiC}$ tubular reactor, ${ }^{43}$ set to dissipate a fixed amount of power using a current-regulated power supply. During operation of the molecular beam the source chamber was kept at a fixed pressure of $6.0 \times 10^{-5}$ Torr. Two skimmers separated the source chamber and main scattering chamber, and collimated the molecular beam.

In the main chamber, the beam passed through an aperture in a copper cold head held at $10 \mathrm{~K}$ by a $\mathrm{He}$ compressor. This surface further collimates the beam and lowers background signal in the detector, maintaining a main chamber pressure of $\sim 5 \times 10^{-7}$ Torr. The detector lies within a triply differentially pumped chamber. A tunable electron impact ring-filament ionizer typically operated at $80 \mathrm{eV}$ creates cations. ${ }^{44}$ These ions are extracted and focused into a quadrupole mass filter which selectively transmits ions according to their $m / z$ value. Mass-selected ions are detected using a Daly-style ion detector. ${ }^{45}$

The molecular beam can be characterized by directing it into the detector, where dissociative ionization following electron impact will produce a mass spectrum characteristic of molecules within the beam. The ionizer can be operated as low as $\sim 4 \mathrm{eV}$, and measuring ion signal response to changes in electron impact energy with a fixed emission current generates an ionization efficiency curve (IEC). ${ }^{46-47}$ The energyintercept of this curve yields an appearance potential that is expected to match the ionization potential of the species in the beam. Finally, a multichannel scaler interfaced to the ion detector can collect and bin ion signal as a function of time. Insertion of a slotted spinning disk into the molecular beam path thus enables determination of the molecular beam velocity profile. Cyclohexyl radical beams typically had a velocity of $1600 \mathrm{~m} / \mathrm{s}$ and speed ratios, defined as the beam flow velocity divided by the velocity spread, of $\sim 5$.

During photodissociation experiments, the focused $248 \mathrm{~nm}$ output of an LPX $220 i$ excimer laser crossed the molecular beam at $90^{\circ}$ with a fluence of $375 \mathrm{~mJ} / \mathrm{cm}^{2}$. The laser was operated at half of the $400 \mathrm{~Hz}$ repetition rate of the pulsed valve to enable shot-to-shot background subtraction of signal not attributable to the laser pulse. Photoproduct TOF spectra were collected as a function of detector laboratory angle $\theta_{L A B}$ relative to the molecular beam by rotating the detector within the plane defined by the laser and molecular beams. Typical TOF spectra were collected using a few $10^{5}-10^{6}$ laser shots and simulated using a forward convolution program to determine center-of-mass translational energy distributions for photoproducts. ${ }^{48}$

\section{Theoretical Methods}

The large photon energy in this study motivated consideration of isomerization and dissociation pathways which were not included by Goldsmith et al. ${ }^{33}$ and Gong et al. ${ }^{34}$ in previous work. Energies and vibrational frequencies for the additional minima and transition states were calculated using the $\omega$ B97X-D functional ${ }^{49}$ with the aug-cc-PVTZ basis set ${ }^{50-51}$ implemented in Gaussian 16. ${ }^{52}$ Excited electronic states of cyclohexyl were found using the EOM-CCSD/aug-cc-PVDZ level of theory. ${ }^{53}$

Unimolecular reaction rates for ground-state isomerization and dissociation of cyclohexyl radicals were calculated using microcanonical Rice-Ramsperger-Kassel-Marcus (RRKM) theory, ${ }^{54}$ where elementary rate constants $\mathrm{k}(\mathrm{E})$ are given by:

$$
k(E)=\sigma \frac{W^{\ddagger}\left(E-E_{o}\right)}{h \rho(E)}
$$


In the above expression, $\sigma$ is the reaction path degeneracy, ${ }^{55} W^{\ddagger}\left(E-E_{o}\right)$ is the sum of rovibrational states accessible to the transition state, $\rho(E)$ is the reactant rovibrational density of states, and $h$ is Planck's constant. It is important to treat internal rotors appropriately in the density of states evaluation given their plentitude in many $\mathrm{C}_{6} \mathrm{H}_{11}$ isomers. To determine $\rho(E)$, the rotational density of states for a collection of $u$ 1-D and $p$ 2-D internal rotors was first calculated according to

$$
\rho_{R}(E)=\frac{\pi^{u / 2}}{\Gamma(p+u / 2)} E^{p+u / 2-1} \prod_{i=1}^{u} \frac{1}{\sigma_{i}}\left(\frac{1}{B_{i}}\right)^{1 / 2} \prod_{j=1}^{p} \frac{1}{\sigma_{j} B_{j}}
$$

where $\sigma_{i}$ is the symmetry number of the internal rotor and $B_{i}$ is the rotational constant. ${ }^{56-57} \mathrm{With}$ the prepared $\rho_{R}(E)$ as a starting point, the Beyer-Swinehart direct-count algorithm was then used to fold in the vibrational density of states to evaluate the full $\rho(E)$ and $W^{\ddagger}\left(E-E_{o}\right)$ required in Equation $1 .^{58}$ Tunneling effects on reaction rates were neglected. Relative product yields were determined by numerically solving the full system of differential equations describing isomerization and dissociation of cyclohexyl.

\section{Results}

\section{Cyclohexyl radical production}

The mass spectrum of cyclohexylmethyl nitrite without pyrolysis is shown in Figure 1. As is typical for electron impact ionization of alkyl nitrites, the parent ion of this species at $m / z=147$ is not observed. ${ }^{59}$ The peak at $m / z=97$ is due to $\mathrm{C}_{7} \mathrm{H}_{13}{ }^{+}$formed when cyclohexylmethyl nitrite cracks in the ionizer. When pyrolysis is turned on this peak is depleted, leaving $\mathrm{m} / \mathrm{z}=83$ as the heaviest ion in line with expectations for cyclohexyl radical. It is important to fully deplete the parent nitrite, since photodissociation of alkyl nitrites can interfere with the ability to determine radical photodissociation channels. ${ }^{60}$ Full nitrite depletion requires dissipating $\sim 28-30 \mathrm{~W}$ in the pyrolysis source. The resulting mass spectrum agrees well with a previously reported partial mass spectrum for cyclohexyl radical produced by H-abstraction from cyclohexane. ${ }^{61}$
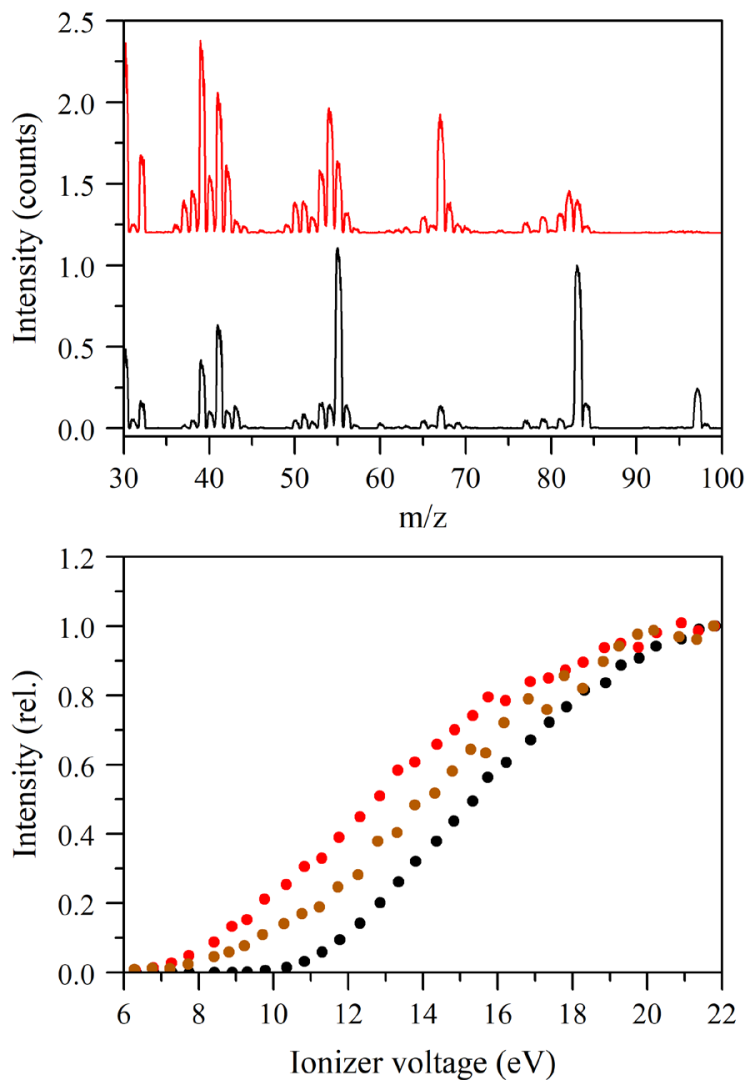

Figure 1. Mass spectra (top) and ionization efficiency curves (IEC, bottom) demonstrating cyclohexyl production. Data for the pyrolysis source off are shown in black, while data for $30 \mathrm{~W}$ power dissipation are shown in red. An IEC is included for $35 \mathrm{~W}$ dissipation power (brown) showing beam contamination under these conditions. 
Further confirmation of cyclohexyl production is obtained by measuring the IEC with and without pyrolysis (Figure 1). Cracking of cyclohexylmethyl nitrite in the ionizer produces $m / z=83$ with an appearance potential of $11.3 \mathrm{eV}$ based on extrapolation of the linear portion of the IEC. When pyrolysis is used to deplete the precursor nitrite, the appearance potential for $m / z=83$ shifts to $7.4 \mathrm{eV}$, close to the known ionization potential of $7.66 \mathrm{eV}$ for cyclohexyl radical. ${ }^{38}$ Increasing the pyrolysis source power from $30 \mathrm{~W}$ to $35 \mathrm{~W}$ produces an IEC with at least two features. The first has an appearance potential $\sim 7.8 \mathrm{eV}$ and is attributed to cyclohexyl radicals, while the second has an appearance potential $\sim 9 \mathrm{eV}$ and is likely caused by isomerization of cyclohexyl to other $\mathrm{C}_{6} \mathrm{H}_{11}$ species via ring-opening. The pyrolysis source was therefore operated close to $30 \mathrm{~W}$ at all times to ensure no other isomers contaminated the molecular beam.

\section{Photofragment translational spectroscopy}

Photofragment product TOF spectra were collected at several angles for many different $\mathrm{m} / \mathrm{z}$ values. Figure 2 shows representative examples for $m / z=82\left(\mathrm{C}_{6} \mathrm{H}_{10}{ }^{+}\right), m / \mathrm{z}=81\left(\mathrm{C}_{6} \mathrm{H}_{9}{ }^{+}\right), m / \mathrm{z}=68\left(\mathrm{C}_{5} \mathrm{H}_{8}{ }^{+}\right), m / \mathrm{z}=67$ $\left(\mathrm{C}_{5} \mathrm{H}_{7}{ }^{+}\right), m / \mathrm{z}=55\left(\mathrm{C}_{4} \mathrm{H}_{7}{ }^{+}\right), m / \mathrm{z}=54\left(\mathrm{C}_{4} \mathrm{H}_{6}{ }^{+}\right), m / \mathrm{z}=41\left(\mathrm{C}_{3} \mathrm{H}_{5}{ }^{+}\right), \mathrm{m} / \mathrm{z}=39\left(\mathrm{C}_{3} \mathrm{H}_{3}{ }^{+}\right), \mathrm{m} / \mathrm{z}=27\left(\mathrm{C}_{2} \mathrm{H}_{3}{ }^{+}\right)$and $m / \mathrm{z}$ $=15\left(\mathrm{CH}_{3}{ }^{+}\right)$. The ionizer was operated at $80 \mathrm{eV}$ during collection of these spectra.

The heaviest possible photofragments from cyclohexyl radical are $\mathrm{C}_{6} \mathrm{H}_{10}$ isomers produced by $\mathrm{H}$-atom loss and having $m / z=82$ parent ions. Ion signal at $m / z=82\left(\mathrm{C}_{6} \mathrm{H}_{10}{ }^{+}\right)$and $m / z=81\left(\mathrm{C}_{6} \mathrm{H}_{9}{ }^{+}\right)$was detected out to $\Theta_{L A B}=12^{\circ}$. Both ions give essentially identical TOF spectra, suggesting that $\mathrm{C}_{6} \mathrm{H}_{9}{ }^{+}$originates from dissociative ionization of $\mathrm{C}_{6} \mathrm{H}_{10}{ }^{+}$ions, and not from an $\mathrm{H}_{2}$-loss pathway. Higher quality TOF spectra were collected at $m / z=81$ given lower background counts for this ion, possibly as a consequence of undissociated cyclohexyl radical preferentially forming $m / z=82$ in the ionizer (see Figure 1). Collecting TOF data for the $\mathrm{H}$-atom counter-fragment is not feasible on this apparatus under these experimental conditions.

For photofragments lighter than $\mathrm{C}_{6} \mathrm{H}_{10}$, the TOF spectra collected at $\Theta_{L A B}<8^{\circ}$ are in general dominated by a feature with a similar arrival time as the $m / z=82$ and 81 spectra. For $8^{\circ} \leq \Theta_{L A B} \leq 12^{\circ}$, a faster feature is observed in many of the TOF spectra, and for $\Theta_{L A B}>12^{\circ}$ only the faster feature remains. These faster TOF features extend across a large range of scattering angles (typically up to our maximum accessible $\theta_{L A B} \approx$ $\left.45^{\circ}\right)$ and are indicative of photoproducts caused by dissociation channels other than $\mathrm{H}$-atom loss. No TOF signal was observable for $m / \mathrm{z}=42\left(\mathrm{C}_{3} \mathrm{H}_{6}{ }^{+}\right)$or $m / \mathrm{z}=29\left(\mathrm{C}_{2} \mathrm{H}_{5}{ }^{+}\right)$despite considerable effort.

All TOF features measured in this experiment are attributed to single-photon excitations based on a linear signal response to changes in laser fluence. Determination of which reaction pathways contribute to TOF signal at different $\mathrm{m} / \mathrm{z}$ values and at different scattering angles is covered in Section V.

\section{Calculations}

The ground-state geometry of cyclohexyl radical is shown in Figure 3a, demonstrating the roughly trigonal planar geometry of the $\alpha$-carbon site. Also shown in Figure $3 \mathrm{~b}$ is a transition state on the ground-state surface with an $\mathrm{H}$ atom forming a bridge between two adjacent carbon atoms. The relevance of this structure to cyclohexyl photochemistry is discussed later. The Supporting Information includes isomerization and dissociation pathways previously neglected by Gong et al. and Goldsmith et al., ${ }^{33-34}$ and calculated for the ground-state surface herein. Many additional H-loss channels were identified, as well as two additional $\mathrm{CH}_{3}$-loss channels. It is important to include these to ensure that statistical calculations produce realistic predictions for different product yields. 


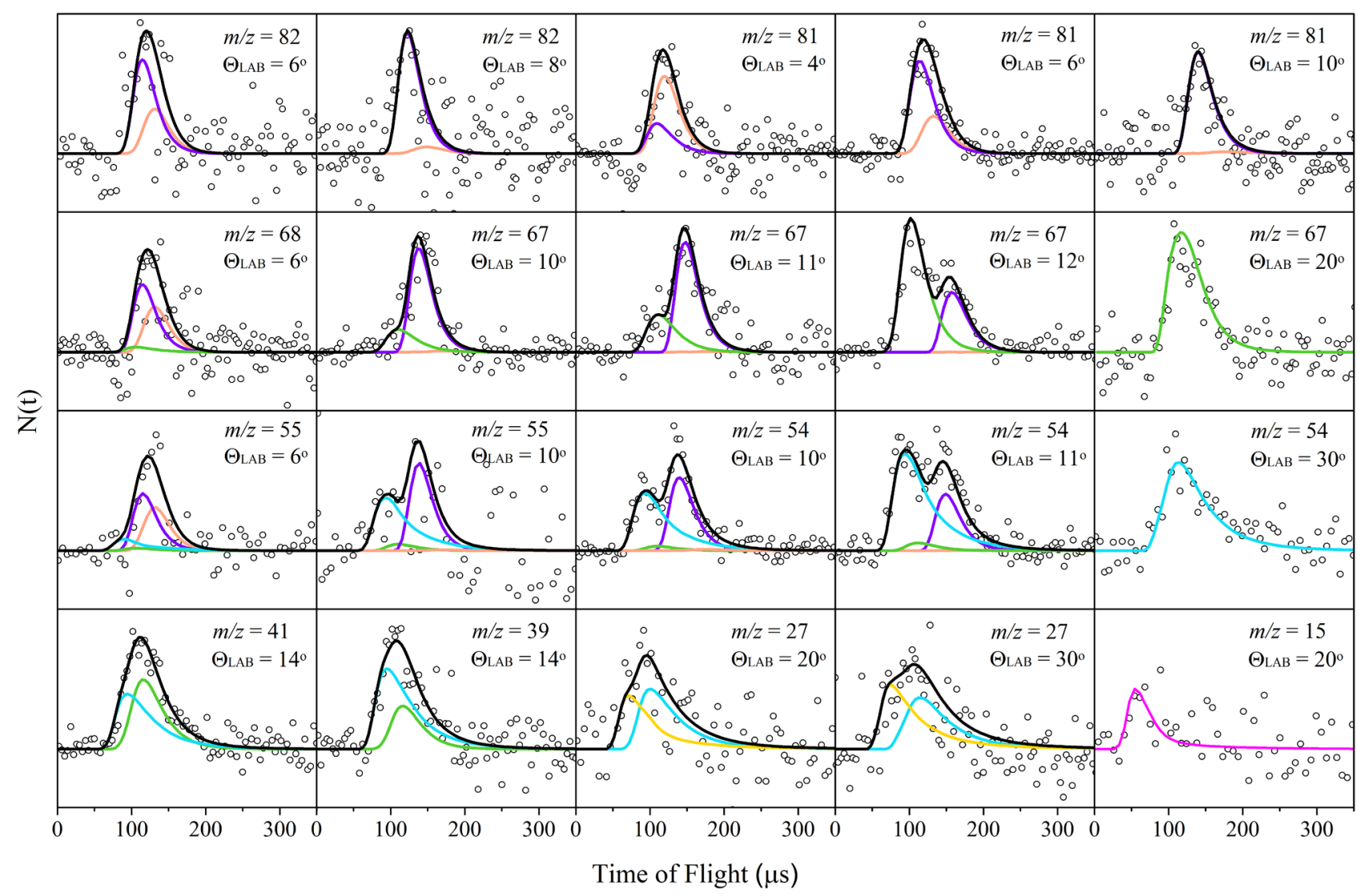

Figure 2. Select TOF spectra for cyclohexyl radical photodissociation. The individual ion $\mathrm{m} / \mathrm{z}$ values and laboratory-frame scattering angles are indicated on each spectrum. Simulations are forward convolutions from the $\mathrm{P}\left(\mathrm{E}_{\mathrm{T}}\right)$ distributions in Figure 4 (purple and orange), Figure 5 (green and magenta), and Figure 6 (blue and gold). For TOF simulations containing multiple components, the total simulation is shown in black.

a

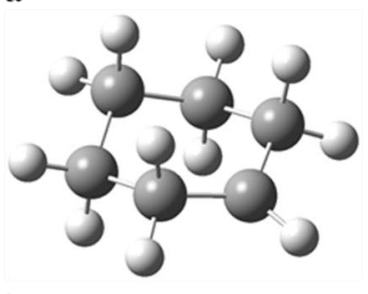

b

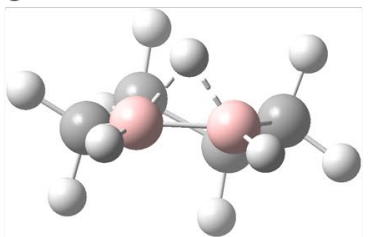

$\mathrm{c}$



d

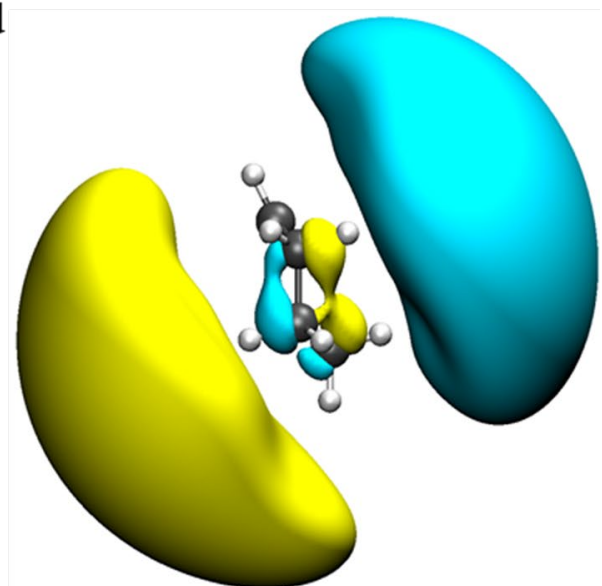

Figure 3. (a) Ground-state equilibrium geometry of cyclohexyl, (b) ground state local maximum with an $\mathrm{H}$ atom bridging two carbons (highlighted pink for viewing clarity), (c) Rydberg 3s orbital isosurface, and (d) Rydberg $3 p_{z}$ orbital isosurface. The Rydberg orbitals are shown with a side-on view of the cyclohexyl ring, with the radical carbon situated in the upper-left (isovalue $=0.01$ a.u.). 
The EOM-CCSD calculations provided excited state properties for cyclohexyl radical. The first excited state is located at $4.54 \mathrm{eV}$ excitation energy, with an oscillator strength of 0.0033 and $\mathrm{A}^{\prime}$ symmetry. The second excited state lies $5.08 \mathrm{eV}$ above the ground state, with oscillator strength of 0.0357 and also $\mathrm{A}^{\prime}$ symmetry. Isosurfaces of the orbitals carrying the greatest amplitude for these excitations are shown in Figure $3 \mathrm{c}$ and $3 \mathrm{~d}$ respectively, both of which are extremely large and diffuse. The lower excitation is to a Rydberg 3s orbital $\left(\widetilde{\mathrm{A}}^{2} \mathrm{~A}^{\prime}\right)$, while the higher is to a Rydberg $3 \mathrm{p}_{z}$ orbital $\left(\widetilde{\mathrm{B}}^{2} \mathrm{~A}^{\prime}\right)$. The latter carries a large oscillator strength and lies very close to the excitation laser energy of $5.0 \mathrm{eV}$ used in this experiment.

\section{Analysis}

Conservation of energy during photodissociation requires

$$
E_{\text {avail }}=h v+E_{i}-D_{o}=E_{\text {int }}+E_{T}
$$

for photon energy $h v$, reactant initial energy $E_{i}$, and dissociation energy $D_{o}$. We assume $E_{i} \approx 0 \mathrm{kcal} / \mathrm{mol}$ for the radical beam following supersonic expansion, in line with previous findings. ${ }^{62-64}$ During dissociation, the available energy $E_{\text {avail }}$ is partitioned into either product internal energy $E_{\text {int }}$ or relative product translational energy $E_{T}$. Conservation of momentum in each dissociation event requires that photofragment pairs acquire equal and opposite momenta. These conservation requirements impose kinematic constraints on the laboratory-frame scattering angles accessible for each dissociation channel.

For $\mathrm{H}$-atom loss to produce cyclohexene, the maximum laboratory angle for the $\mathrm{C}_{6} \mathrm{H}_{10}$ photofragment is $\theta_{L A B}=12^{\circ}$, with no constraint on the $\mathrm{H}$-atom fragment. The possible production of $\mathrm{H}$-atoms from other reasonable $\mathrm{C}_{6} \mathrm{H}_{11}$ isomers does not change this angular constraint significantly. A similar analysis for methyl-loss indicates a maximum $\theta_{L A B}=52-61^{\circ}$ for different $\mathrm{C}_{5} \mathrm{H}_{8}$ fragments, with no constraint on $\mathrm{CH}_{3}$. Other dissociation channels have no kinematic constraints on accessible scattering angles.

Product TOF spectra for each dissociation channel are governed by the joint center-of-mass translational energy and angular distribution, $P\left(E_{T}, \theta\right)$. Decoupling this distribution into separate center-of-mass translational energy and angular distributions yields

where $I(\theta)$ has the functional form

$$
P\left(E_{T}, \theta\right)=P\left(E_{T}\right) I(\theta)
$$

$$
I(\theta)=\frac{1}{4 \pi}\left[1+\beta P_{2}(\cos \theta)\right]
$$

with anisotropy parameter $\beta$ and second Legendre polynomial $P_{2}(a)=\frac{1}{2}\left(3 a^{2}-1\right){ }^{65}$

The $\mathrm{P}\left(\mathrm{E}_{\mathrm{T}}\right)$ distribution used to simulate $\mathrm{C}_{6} \mathrm{H}_{11} \rightarrow \mathrm{C}_{6} \mathrm{H}_{10}+\mathrm{H}$ is shown in Figure 4, which provides the best simulation to the data collected at $m / z=82\left(\mathrm{C}_{6} \mathrm{H}_{10}{ }^{+}\right)$and $m / z=81\left(\mathrm{C}_{6} \mathrm{H}_{9}{ }^{+}\right)$. Measuring TOF spectra at $\mathrm{m} / \mathrm{z}$ $=1$ for the $\mathrm{H}$-atom counter-fragment is infeasible due to the short residence time of $\mathrm{H}$ atoms in the ionizer, their small ionization cross-section, and high detector background at this $m / z$, as well as detection of $\mathrm{H}-$ atoms being kinematically disfavored. The bimodal distribution in Figure 4 extends up to the available energy of $84 \mathrm{kcal} / \mathrm{mol}$ for $\mathrm{H}$-atom loss, and is deconvoluted into a 'fast' and 'slow' feature. For the slow feature we take $\beta=0$ for the anisotropy parameter, while for the fast we take $\beta=0.5$ in accord with previous findings of other alkyl radicals and with unpublished work on cyclohexyl $\mathrm{H}$-atom loss at the same laser wavelength. ${ }^{19-22}$ The $\mathrm{P}\left(\mathrm{E}_{\mathrm{T}}\right)$ distribution reported previously by measuring $\mathrm{H}$-atoms is also shown for comparison. $^{22}$ 


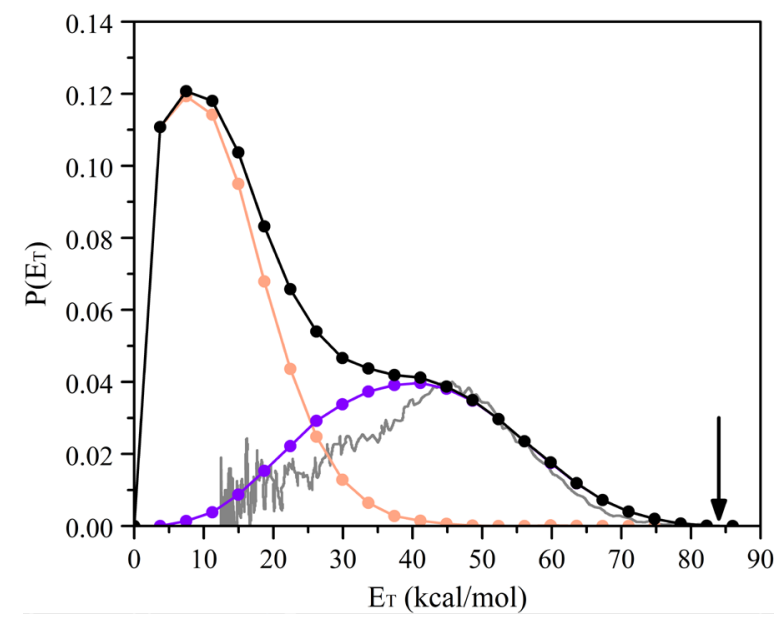

Figure 4. $\mathrm{P}\left(\mathrm{E}_{\mathrm{T}}\right)$ for $\mathrm{C}_{6} \mathrm{H}_{11} \rightarrow \mathrm{C}_{6} \mathrm{H}_{10}+\mathrm{H}$. The black distribution provides the best simulation of the experimental data. This overall distribution is separated into a slow and a fast feature. This $\mathrm{P}\left(\mathrm{E}_{\mathrm{T}}\right)$ produces the orange and purple TOF simulations in Figure 2 for 'slow' and 'fast' $\mathrm{C}_{6} \mathrm{H}_{10}$ respectively. The gray distribution is the $\mathrm{H}$-atom $\mathrm{P}\left(\mathrm{E}_{\mathrm{T}}\right)$ reported previously. ${ }^{22}$ The available energy for cyclohexene formation is indicated by the black arrow.

The $\mathrm{P}\left(\mathrm{E}_{\mathrm{T}}\right)$ used to simulate $\mathrm{C}_{6} \mathrm{H}_{11} \rightarrow \mathrm{C}_{5} \mathrm{H}_{8}+\mathrm{CH}_{3}$ is shown in Figure 5, determined using the TOF spectra collected at $m / z=68\left(\mathrm{C}_{5} \mathrm{H}_{8}{ }^{+}\right), m / z=67\left(\mathrm{C}_{5} \mathrm{H}_{7}{ }^{+}\right)$, and $m / z=15\left(\mathrm{CH}_{3}{ }^{+}\right)$. We take $\beta=0$ for this distribution. The distribution extends up to $33 \mathrm{kcal} / \mathrm{mol}$, well below $\mathrm{E}_{\text {avail }}=71-89 \mathrm{kcal} / \mathrm{mol}$ for methyl loss depending on the $\mathrm{C}_{5} \mathrm{H}_{8}$ isomer formed.

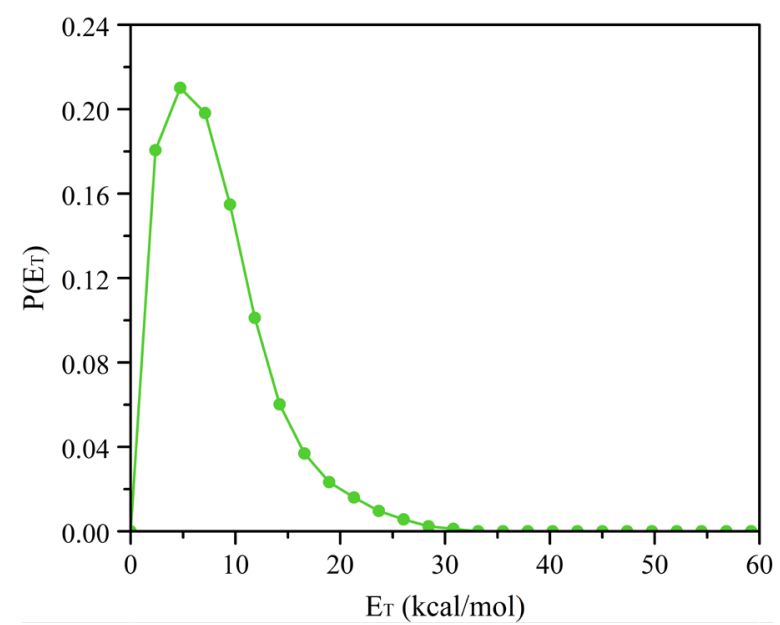

Figure 5. $\mathrm{P}\left(\mathrm{E}_{\mathrm{T}}\right)$ for $\mathrm{C}_{6} \mathrm{H}_{11} \rightarrow \mathrm{C}_{5} \mathrm{H}_{8}+\mathrm{CH}_{3}$, with $\beta=0$. This $\mathrm{P}\left(\mathrm{E}_{\mathrm{T}}\right)$ produces the green and magenta TOF simulations in Figure 2, corresponding to the $\mathrm{C}_{5} \mathrm{H}_{8}$ and $\mathrm{CH}_{3}$ fragments respectively.

The $\mathrm{P}\left(\mathrm{E}_{\mathrm{T}}\right)$ distribution for $\mathrm{C}_{6} \mathrm{H}_{11} \rightarrow \mathrm{C}_{4} \mathrm{H}_{7}+\mathrm{C}_{2} \mathrm{H}_{4}$ is shown in Figure 6, with $\beta=0$ assumed. This distribution gave the best simulation for TOF spectra at $m / z=55\left(\mathrm{C}_{4} \mathrm{H}_{7}{ }^{+}\right), m / z=54\left(\mathrm{C}_{4} \mathrm{H}_{6}{ }^{+}\right)$, and $m / z=27\left(\mathrm{C}_{2} \mathrm{H}_{3}{ }^{+}\right)$. The parent ion of $\mathrm{C}_{2} \mathrm{H}_{4}$ cannot be observed at $m / z=28$ due to high $\mathrm{N}_{2}{ }^{+}$background in the detector, so the daughter ion $m / z=27\left(\mathrm{C}_{2} \mathrm{H}_{3}{ }^{+}\right)$is used instead. The distribution extends up to $47 \mathrm{kcal} / \mathrm{mol}$, with $\mathrm{E}_{\text {avail }}=72$ $\mathrm{kcal} / \mathrm{mol}$ for ethene loss. The very weak signal at $m / z=55\left(\mathrm{C}_{4} \mathrm{H}_{7}^{+}\right)$relative to 54 in Figure 2 (see results at $\left.\Theta_{\mathrm{LAB}}=10^{\circ}\right)$ is discussed later in this section. 


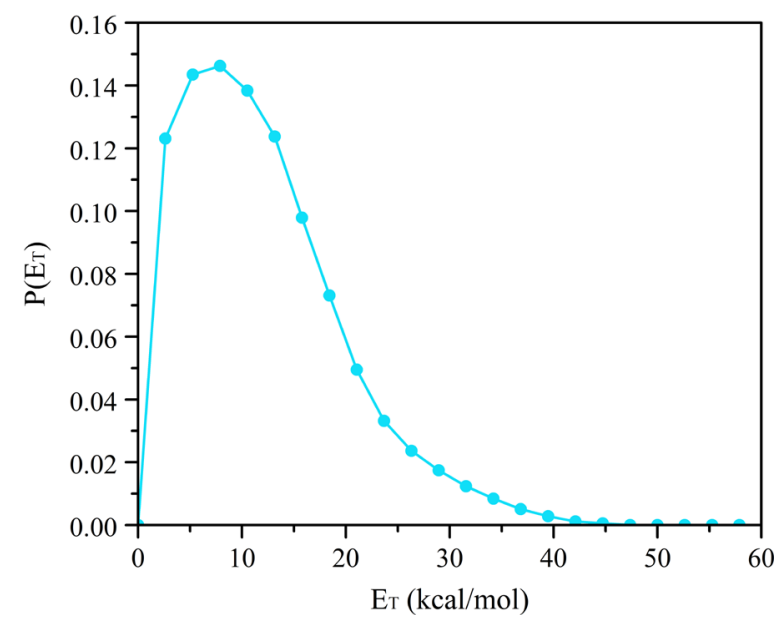

Figure 6. $\mathrm{P}\left(\mathrm{E}_{\mathrm{T}}\right)$ for $\mathrm{C}_{6} \mathrm{H}_{11} \rightarrow \mathrm{C}_{4} \mathrm{H}_{7}+\mathrm{C}_{2} \mathrm{H}_{4}$, with $\beta=0$. This $\mathrm{P}\left(\mathrm{E}_{\mathrm{T}}\right)$ produces the blue and gold TOF simulations in Figure 2, corresponding to the $\mathrm{C}_{4} \mathrm{H}_{7}$ and $\mathrm{C}_{2} \mathrm{H}_{4}$ fragments respectively.

All other TOF spectra could be simulated using a combination of these three $\mathrm{P}\left(\mathrm{E}_{\mathrm{T}}\right)$ distributions. The distributions are compared in Table 2 across several key characteristics: the peak of the distribution, the average translational energy $\left\langle\mathrm{E}_{\mathrm{T}}\right\rangle$, the maximum translational energy $\mathrm{E}_{\mathrm{T}}^{\max }$, and the fraction of available energy partitioned into relative product translation $\left\langle f_{T}\right\rangle$. The values of $\mathrm{E}_{\mathrm{T}}^{\max }$ and $\left\langle f_{T}\right\rangle$ presuppose all photoproducts are formed in their ground electronic states.

Table 2. Characteristics of the $\mathrm{P}\left(\mathrm{E}_{\mathrm{T}}\right)$ distributions for cyclohexyl dissociation. All values are in $\mathrm{kcal} / \mathrm{mol}$ except for $\left\langle f_{\mathrm{T}}\right\rangle$ which is a dimensionless quantity ranging from 0 to 1 .

\begin{tabular}{ccccc} 
Channel & Peak & $\left\langle\mathbf{E}_{\mathbf{T}}\right\rangle$ & $\mathbf{E}_{\mathbf{T}}^{\text {max }}$ & $\left\langle\boldsymbol{f}_{\mathbf{T}}\right\rangle$ \\
\hline $\mathrm{C}_{6} \mathrm{H}_{10}+\mathrm{H}$ & & & & \\
Slow & 7 & 13 & 65 & 0.15 \\
Fast & 41 & 40 & 84 & 0.48 \\
$\mathrm{C}_{5} \mathrm{H}_{8}+\mathrm{CH}_{3}$ & 5 & 8 & 33 & 0.10 \\
$\mathrm{C}_{4} \mathrm{H}_{7}+\mathrm{C}_{2} \mathrm{H}_{4}$ & 8 & 12 & 47 & 0.17
\end{tabular}

The branching ratio between pairs of different product channels may be extracted from TOF spectra containing contributions from both channels according to

$$
B R\left(\frac{A}{B}\right)=\frac{W_{A}}{W_{B}} \times \frac{\sigma_{B}}{\sigma_{A}} \times \frac{f_{B}}{f_{A}}
$$

in which $W_{i}$ is the weighting of the $P\left(E_{T}\right)$ for channel $i, \sigma_{i}$ is the ionization cross-section for product $i$, and $f_{i}$ is the fraction of product $i$ that dissociatively ionizes to the measured $m / z$. In this work, the relative ionization cross-sections of different products are estimated according to an empirical scheme, ${ }^{66}$ and $f_{i}$ values are taken from published mass spectra. ${ }^{67-69}$ Figure 2 shows many examples of TOF spectra simulated using components from multiple dissociation channels which can be used to calculate product branching ratios. These calculations produce the relative product yields shown in Table 3, normalized with respect to the slow H-loss channel. The uncertainty in these ratios is determined by varying $W_{i}$ for each component until agreement between simulation and data becomes unsatisfactory (e.g. see Supporting Information for discussion of the bimodal H-loss distributions).

Calculated RRKM branching ratios for ground-state statistical dissociation of cyclohexyl radicals are also included in Table 3, expressed relative to the amount of H-atom loss. Since the RRKM analysis is applied only to the ground-state dissociation pathways, the fast $\mathrm{H}$-loss channel is not included. The only dissociation channel directly accessible to cyclohexyl is H-loss to form cyclohexene, and this is the dominant channel 
identified in the RRKM analysis. To form any other products, the first step must always be ring-opening to 1-hexen-6-yl, with additional isomerization also usually required. Differentiating between isomer yields, these calculations indicate that cyclohexene accounts for $92 \%$ of all ground-state $\mathrm{H}$-loss reactions. All other $\mathrm{H}$-loss channels contribute well below 1\% except for 1,5-hexadiene and 4-methyl-1,3-pentadiene, which each account for $3.6 \%$ of $\mathrm{C}_{6} \mathrm{H}_{10}$. Within the $\mathrm{CH}_{3}$-loss channels considered, the predicted yields of 1,3pentadiene, cyclopentene, and 1,4-pentadiene were $76 \%, 14 \%$ and $10 \%$ respectively. If cyclohexyl radicals were to undergo ring-opening in the pyrolysis source, the RRKM product branching changes dramatically (see Supporting Information).

Table 3. Experimental and RRKM branching ratios and approximate experimental yields for cyclohexyl photodissociation. All ratios are expressed relative to the yield of the slow $\mathrm{H}$-loss channel.

\begin{tabular}{|c|c|c|c|}
\hline \multirow{2}{*}{ Channel } & \multicolumn{2}{|c|}{ Branching ratio } & \multirow{2}{*}{$\begin{array}{c}\text { Percent } \\
\text { Yield }\end{array}$} \\
\hline & Experimental & RRKM & \\
\hline \multicolumn{4}{|l|}{$\mathrm{C}_{6} \mathrm{H}_{10}+\mathrm{H}$} \\
\hline Total & $1.7_{-0.4}^{+1.6}$ & - & 66 \\
\hline Slow & 1 & 1 & 39 \\
\hline Fast & $0.7_{-0.4}^{+1.6}$ & - & 27 \\
\hline $\mathrm{C}_{5} \mathrm{H}_{8}+\mathrm{CH}_{3}$ & $0.015_{-0.005}^{+0.005}$ & 0.0037 & 1 \\
\hline $\mathrm{C}_{4} \mathrm{H}_{7}+\mathrm{C}_{2} \mathrm{H}_{4}$ & $0.86_{-0.07}^{+0.10}$ & 0.80 & 33 \\
\hline $\mathrm{C}_{4} \mathrm{H}_{6}+\mathrm{C}_{2} \mathrm{H}_{5}$ & Not observed & 0.019 & 0 \\
\hline $\mathrm{C}_{3} \mathrm{H}_{6}+\mathrm{C}_{3} \mathrm{H}_{5}$ & Not observed & 0.0071 & 0 \\
\hline
\end{tabular}

Distinguishing between the $\mathrm{C}_{4} \mathrm{H}_{7}+\mathrm{C}_{2} \mathrm{H}_{4}$ and $\mathrm{C}_{4} \mathrm{H}_{6}+\mathrm{C}_{2} \mathrm{H}_{5}$ channels is challenging in this experiment. These channels should give parent ions with $\mathrm{m} / z=55$ and 28 , and $\mathrm{m} / z=54$ and 29 respectively. As described above, while signal levels were favorable for $m / z=54\left(\mathrm{C}_{4} \mathrm{H}_{6}{ }^{+}\right)$and $m / z=27\left(\mathrm{C}_{2} \mathrm{H}_{3}{ }^{+}\right)$, they were very weak for $m / z=55\left(\mathrm{C}_{4} \mathrm{H}_{7}{ }^{+}\right)$and undetectable for $m / z=29\left(\mathrm{C}_{2} \mathrm{H}_{5}{ }^{+}\right)$. The greatest relative ion abundance in the mass spectrum of $\mathrm{C}_{2} \mathrm{H}_{5}$ is for $m / z=29\left(\mathrm{C}_{2} \mathrm{H}_{5}{ }^{+}\right),{ }^{68}$ and the absence of this signal is a strong indicator that the $\mathrm{C}_{4} \mathrm{H}_{6}$ $+\mathrm{C}_{2} \mathrm{H}_{5}$ channel cannot explain the observed data. Hence, we propose that nearly all the signal at these three $m / z$ values is from the $\mathrm{C}_{4} \mathrm{H}_{7}+\mathrm{C}_{2} \mathrm{H}_{4}$ channel, and that $\mathrm{C}_{4} \mathrm{H}_{7}$ is produced with sufficient internal energy to dissociate to $\mathrm{C}_{4} \mathrm{H}_{6}$ in transit to the detector. Arguments in support of this mechanism are as follows.

Unlike other photoproducts in this experiment, the reaction barriers for 1-buten-4-yl are quite low compared to the available energy for the $\mathrm{C}_{4} \mathrm{H}_{7}+\mathrm{C}_{2} \mathrm{H}_{4}$ channel. $\mathrm{H}$-loss to form butadiene requires $28 \mathrm{kcal} / \mathrm{mol}$ whereas dissociation to $\mathrm{C}_{2} \mathrm{H}_{4}+\mathrm{C}_{2} \mathrm{H}_{3}$ requires $34 \mathrm{kcal} / \mathrm{mol}$, with exit barriers of approximately 6 and $5 \mathrm{kcal} / \mathrm{mol}$ respectively. ${ }^{34,70}$ The RRKM branching between these two channels is shown as a function of 1-buten-4-yl internal energy in Figure 7. The relative yields of these two channels varies greatly over the available energy range. The questions then are how much of the available energy is partitioned into 1-buten-4-yl internal degrees of freedom during dissociation of cyclohexyl radicals, and what is the corresponding dissociation rate. 

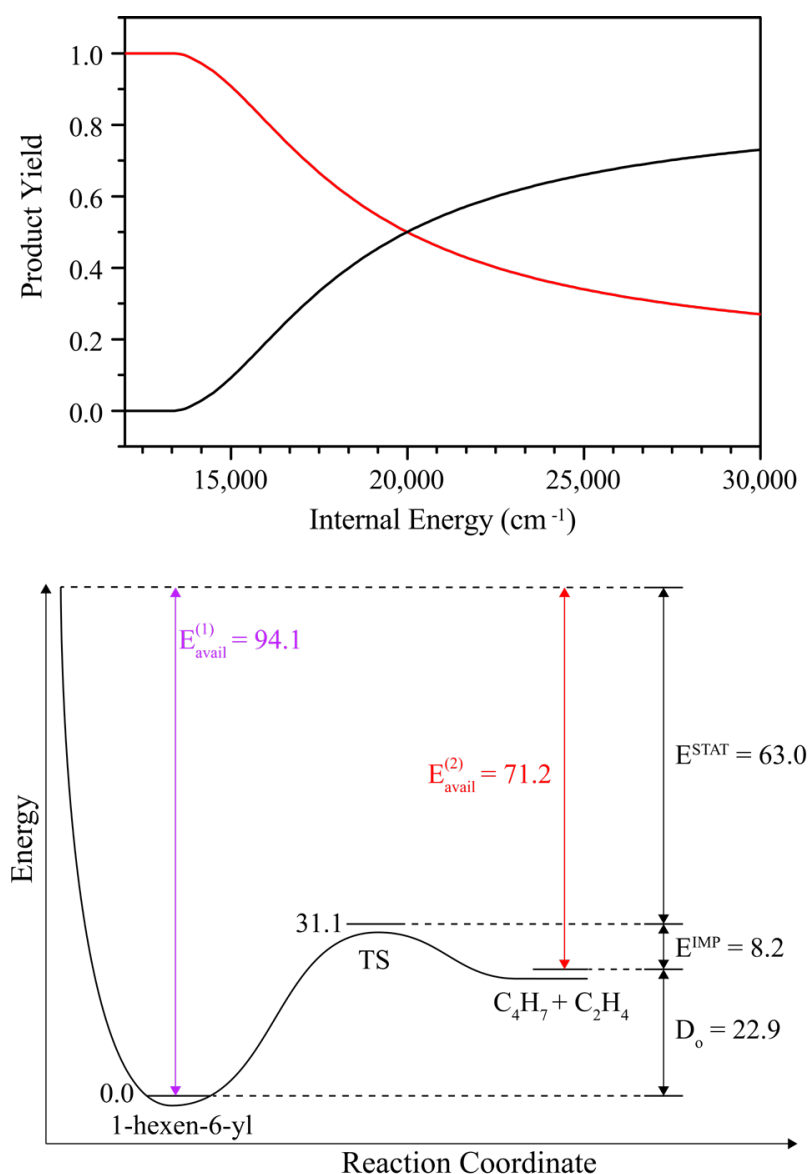

Figure 7. Top panel: RRKM product yield of $\mathrm{C}_{4} \mathrm{H}_{7} \rightarrow \mathrm{C}_{4} \mathrm{H}_{6}+\mathrm{H}$ (red) and $\mathrm{C}_{4} \mathrm{H}_{7} \rightarrow \mathrm{C}_{2} \mathrm{H}_{4}+\mathrm{C}_{2} \mathrm{H}_{3}$ (black) as a function of 1-buten-4-yl internal energy $\left(\mathrm{cm}^{-1}\right)$. Bottom panel: schematic diagram of the 1-hexen-6-yl $\rightarrow$ $\mathrm{C}_{4} \mathrm{H}_{7}+\mathrm{C}_{2} \mathrm{H}_{4}$ reaction coordinate (energies given in units of $\mathrm{kcal} / \mathrm{mol}$ ).

Ring-opening of photoexcited cyclohexyl radical produces 1-hexen-6-yl with $\mathrm{E}_{\text {avail }}^{(1)}=94.1 \mathrm{kcal} / \mathrm{mol}$ of available energy. These 1-hexen-6-yl radicals may then dissociate over a $31.1 \mathrm{kcal} / \mathrm{mol}$ barrier to form 1buten-4-yl + ethene, with $\mathrm{E}_{\text {avail }}^{(2)}=71.2 \mathrm{kcal} / \mathrm{mol}$ of energy available for partitioning between the product fragments. Figure 7 includes a schematic energy diagram of the 1-hexen-6-yl $\rightarrow \mathrm{C}_{4} \mathrm{H}_{7}+\mathrm{C}_{2} \mathrm{H}_{4}$ reaction coordinate. To assess the likelihood of 1-buten-4-yl spontaneous secondary dissociation, we use a model to estimate energy partitioning in the dissociation fragments. The available energy $\mathrm{E}_{\text {avail }}^{(2)}$ is first split into statistical $\left(\mathrm{E}^{\mathrm{STAT}}\right)$ and non-statistical $\left(\mathrm{E}^{\mathrm{IMP}}\right)$ reservoirs (see Figure 7). The statistical reservoir of 63.0 $\mathrm{kcal} / \mathrm{mol}$ corresponds to the energy difference between the full available energy and the energy of the transition state located atop the exit barrier (including zero-point correction). The average values for energy partitioning into various product degrees of freedom are determined by applying a simple statistical model relating microcanonical to canonical energy partitioning. ${ }^{71}$ In this model, the available energy is partitioned into relative translation, total rotation of both fragments, and vibrations of individual fragments according to:

$$
\begin{aligned}
E_{\text {avail }} & =\left\langle E_{T}\right\rangle+\left\langle E_{R}\right\rangle_{\text {tot }}+\left\langle E_{V}\right\rangle_{1}+\left\langle E_{V}\right\rangle_{2} \\
& =k_{B} T^{*}+\frac{r-1}{2} k_{B} T^{*}+\sum_{i=1}^{s_{1}} \frac{h v_{i}}{\exp \left[h v_{i} / k_{B} T^{*}\right]-1}+\sum_{i=1}^{S_{2}} \frac{h v_{i}}{\exp \left[h v_{i} / k_{B} T^{*}\right]-1}
\end{aligned}
$$

In this expression, $r$ is the total number of rotational degrees of freedom for both products, $s_{1}$ and $s_{2}$ are the number of vibrational modes available to $\mathrm{C}_{4} \mathrm{H}_{7}$ and $\mathrm{C}_{2} \mathrm{H}_{4}$ and $v_{i}$ their frequencies, $k_{B}$ is the Boltzmann constant and $\mathrm{T}^{*}$ is the effective product temperature. Evaluating Equation 7 as a function of $\mathrm{T}^{*}$ enables a correlation between $\mathrm{T}^{*}$ and $\mathrm{E}_{\text {avail }}$. This model assumes equilibrium between the translational, rotational, 
and vibrational degrees of freedom, subject to constraints ensuring conservation of angular momentum. The translational and rotational degrees of freedom thus take on values $1 / 2 k_{\mathrm{B}} \mathrm{T}^{*}$ less than their classical equipartition expressions. The vibrational modes are treated quantum mechanically since their energy spacing is significant compared to the available energy. This model has shown excellent agreement for the dissociation of other neutral species, such as styrene $\rightarrow$ benzene + acetylene, with very similar available energy and internal degrees of freedom as 1-hexen-6-yl considered here. ${ }^{72-73}$

The $63.0 \mathrm{kcal} / \mathrm{mol}$ of available energy in the statistical reservoir is satisfied for $\mathrm{T}^{*}=1476 \mathrm{~K}$ in Equation 7 . The model then predicts $\left\langle E_{T}\right\rangle=3.0 \mathrm{kcal} / \mathrm{mol}$ of relative fragment motion, and a combined value of $\left\langle E_{R}\right\rangle_{\text {tot }}$ $=7.4 \mathrm{kcal} / \mathrm{mol}$ of total external fragment rotations. The value of $\left\langle E_{T}\right\rangle$ from this model is not expected to correspond to the experimental value given in Table 2 for two reasons. Firstly, the influence of the exit barrier is not included here, and this barrier is expected to yield faster relative motion of the two fragments. Additionally, a two-step dissociation process leading to the observed photofragment signal would lead to an experimental translational energy distribution which is a convolution of the distributions for the individual reaction steps. This broadens the experimental translational energy distribution and skews $\left\langle E_{T}\right\rangle$ to higher values.

The model predicts $62 \%$ of the statistical reservoir is partitioned into $\mathrm{C}_{4} \mathrm{H}_{7}$ vibrational modes. The partitioning of the remaining $8.2 \mathrm{kcal} / \mathrm{mol}$ in the non-statistical reservoir is subject to the influence of the exit barrier in a non-trivial way. Based on the very non-rigid structure of 1-hexen-6-yl and the geometry of the transition state, it is expected that an additional few $\mathrm{kcal} / \mathrm{mol}$ are partitioned into $\mathrm{C}_{4} \mathrm{H}_{7}$ vibrations. We take the average internal energy of nascent $\mathrm{C}_{4} \mathrm{H}_{7}$ to be $\sim 40 \mathrm{kcal} / \mathrm{mol}\left(\sim 14,000 \mathrm{~cm}^{-1}\right)$. The RRKM analysis for $14,000 \mathrm{~cm}^{-1}$ of available energy suggests that on average, 1-buten-4-yl dissociates to $\mathrm{C}_{4} \mathrm{H}_{6}+\mathrm{H}$ and $\mathrm{C}_{2} \mathrm{H}_{4}$ $+\mathrm{C}_{2} \mathrm{H}_{3}$ in a 98:2 ratio, and that these reactions only take $\sim 1 \mu$ s to occur completely. Thus, all the $\mathrm{C}_{4} \mathrm{H}_{7}$ dissociates in transit to the detector, and since nearly all of this dissociation proceeds via statistical $\mathrm{H}$-atom loss, the time-of-flight spectrum measured for $\mathrm{C}_{4} \mathrm{H}_{6}$ will be very similar to that for undissociated $\mathrm{C}_{4} \mathrm{H}_{7}$. The $\mathrm{C}_{2} \mathrm{H}_{3}$ from this channel will be formed in amounts likely too small to be distinguished from dissociative ionization of other, more numerous photoproducts.

The $m / z=54$ ion signal in this experiment is thus associated with 1,3-butadiene from dissociated $\mathrm{C}_{4} \mathrm{H}_{7}$ that will be formed in essentially equal amounts to $\mathrm{C}_{2} \mathrm{H}_{4}$. A branching ratio was extracted from the $m / z=27$ $\left(\mathrm{C}_{2} \mathrm{H}_{3}{ }^{+}\right)$TOF spectra, which contain simulations from both components of the $\mathrm{C}_{4} \mathrm{H}_{7}+\mathrm{C}_{2} \mathrm{H}_{4}$ channel. In light of the above, the calculation uses $\sigma_{i}$ and $f_{i}$ values for 1,3-butadiene and ethene. $\mathrm{The}^{\mathrm{C}_{4} \mathrm{H}_{6}}: \mathrm{C}_{2} \mathrm{H}_{4}$ branching ratio of $0.98_{-0.35}^{+0.22}$ is consistent with the same dissociation event ultimately giving rise to both of these fragments.

A similar analysis was done for the $\mathrm{C}_{4} \mathrm{H}_{6}+\mathrm{C}_{2} \mathrm{H}_{5}$ channel since secondary $\mathrm{H}$-loss from ethyl could explain the lack of signal at $m / z=29$. Considering the available energy for this channel, the model predicts that ethyl radicals will have insufficient energy to lose $\mathrm{H}$ atoms, even in the unphysical scenario in which the entirety of the exit barrier is partitioned into product internal energy. In fact, $\mathrm{C}_{4} \mathrm{H}_{7}$ is the only photofragment expected to be formed with sufficient internal energy to undergo secondary dissociation.

\section{Discussion}

This experiment investigates the photochemistry of cyclohexyl radicals at $248 \mathrm{~nm}$ to determine the yield of different possible photoproducts and the dissociation mechanisms that produce them. This wavelength corresponds to excitation to the 3p Rydberg state of cyclohexyl and results in liberation of an $\mathrm{H}$ atom. As with ethyl radical, photoexcitation is localized on a different $\mathrm{C}$ atom from which $\mathrm{H}$-atom loss occurs. 
Dissociation formally occurs from a $\mathrm{C}$ atom adjacent to the radical site to produce cyclohexene, but this process involves a bridged structure with $\mathrm{H}$ equidistant from two $\mathrm{C}$ atoms. In addition to $\mathrm{H}$-loss, we observe $\mathrm{C}_{5} \mathrm{H}_{8}+\mathrm{CH}_{3}$ and $\mathrm{C}_{4} \mathrm{H}_{7}+\mathrm{C}_{2} \mathrm{H}_{4}$ channels, with $\mathrm{C}_{4} \mathrm{H}_{7}$ further decomposing to $\mathrm{C}_{4} \mathrm{H}_{6}+\mathrm{H}$.

The excited state mechanism observed here is presumably similar to that extensively characterized for $\mathrm{H}-$ atom loss from the ethyl radical excited to its $3 \mathrm{~s}$ and $3 \mathrm{p}$ Rydberg states to form $\mathrm{H}+\mathrm{C}_{2} \mathrm{H}_{4} \cdot{ }^{14-17}$ In both species, $\mathrm{H}$-atom loss does not occur from the radical center, as this would lead to $\mathrm{CH}_{3} \mathrm{CH}+\mathrm{H}$ from ethyl and a similar high energy product here (note that there is evidence for $\mathrm{CH}_{3} \mathrm{CH}$ from ethyl at higher excitation energies than are relevant here ${ }^{16-17}$ ). Excitation of ethyl to the $3 \mathrm{~s}$ state leads to an $\mathrm{H}$-bridged structure with $\mathrm{C}_{2 \mathrm{v}}$ symmetry that is repulsive along the coordinate for dissociation of the bridged $\mathrm{H}$ atom, ${ }^{74}$ and passage through a conical intersection en route to dissociation leads to $\mathrm{H}+$ ground state $\mathrm{C}_{2} \mathrm{H}_{4} \cdot{ }^{16-17}$ Branching at this conical intersection is found by experiment to favor the slow $\mathrm{H}$-atom loss channel. Accessing other curvecrossings requires energies greater than are relevant here. ${ }^{16-17,75-76}$ The observation of very similar kinetic energy release into $\mathrm{H}$-atoms formed from an array of alkyl radicals suggests that, near the excitation threshold, crossing always occurs through this particular H-bridged conical intersection with the ground state. ${ }^{77}$ Excitation to the $3 p$ state of ethyl leads to internal conversion to the $3 \mathrm{~s}$ state, followed by the same dynamical pathway seen following 3s excitation..$^{9,16-17,76}$ The general features for ethyl have also been observed in the photodissociation of other alkyl radicals.

For cyclohexyl excited to the $3 p$ Rydberg state, the dominant dissociation channel is H-atom loss, yielding a bimodal photofragment translational energy distribution very similar to all other alkyl radicals in the literature, with a branching ratio of $\sim 0.7: 1$ for the fast:slow components of the distribution. There is good agreement between the fast component in the translational energy distribution measured herein for $\mathrm{C}_{6} \mathrm{H}_{10}$ and that reported previously using $\mathrm{H}$-atom Rydberg tagging, but that $\mathrm{H}$-atom study did not show the slow component of the distribution. ${ }^{22}$ It is possible the slow component was obscured by the considerable noise evident in the $\mathrm{H}$-atom data.

As with ethyl radical, an H-bridged geometry of cyclohexyl such as shown in Figure $3 \mathrm{~b}$ is presumably responsible for the impulsive cleavage leading to the fast, non-statistical H-loss channel. This pathway partitions an average of $48 \%$ of available energy into relative product translation and extends up to the maximum available energy, accordant with observations of all other alkyl radicals to date. Simulation of TOF data used an anisotropy parameter $\beta>0$, consistent with a parallel electronic transition and a dissociation rate faster than the rotational period of cyclohexyl. By analogy with the dynamics of $3 p$ photoexcited ethyl radicals, we propose that the initially prepared $3 \mathrm{p}$ state internally converts to the $3 \mathrm{~s}$ state, where prompt recoil and dissociation to ground state $\mathrm{H}+\mathrm{C}_{6} \mathrm{H}_{10}$ products occurs through the $\mathrm{H}$-bridged conical intersection. In the case of cyclohexyl this occurs in $\sim 27 \%$ of the excited radicals, and this mechanism leads exclusively to cyclohexene as the $\mathrm{C}_{6} \mathrm{H}_{10}$ photofragment.

The slow H-loss pathway partitions an average of only $15 \%$ of available energy into relative product translation, peaking at low translational energy in line with expectations for statistical dissociation. This channel is thus assigned to statistical dissociation of cyclohexyl radicals, and it is responsible for the greatest fraction of total dissociation, $\sim 39 \%$. It arises by population of the ground state well of cyclohexyl during passage through the conical intersection, followed by intramolecular vibrational energy redistribution. While the potential energy diagrams show nine $\mathrm{H}$-atom loss pathways accessible through isomerization, RRKM calculations suggest cyclohexene is the only non-negligible $\mathrm{C}_{6} \mathrm{H}_{10}$ isomer, accounting for $92 \%$ of $\mathrm{C}_{6} \mathrm{H}_{10}$ photoproduct formed following internal conversion. 
The presence of ground state statistical $\mathrm{H}$-atom loss suggests that several other pathways known on the ground state should also be operative, and this is consistent with our observation of channels other than $\mathrm{H}$ atom loss. We find production of $\mathrm{C}_{4} \mathrm{H}_{7}+\mathrm{C}_{2} \mathrm{H}_{4}$ and $\mathrm{C}_{5} \mathrm{H}_{8}+\mathrm{CH}_{3}$ with generally slow translational energy distributions consistent with statistical dissociation over exit barriers. Assigning these channels to ground state dissociation is further supported by experimental product branching ratios in good agreement with statistical RRKM predictions. Both of these channels begin with ring-opening of cyclohexyl to 1-hexen-6yl, which can dissociate over a barrier to 1-buten-4-yl + ethene. Successive internal H-abstractions by 1hexen-6-yl lead first to 1-hexen-3-yl and then to 2-hexen-4-yl, which dissociates over a barrier to 1,3pentadiene $+\mathrm{CH}_{3}$. Isomers of $\mathrm{C}_{5} \mathrm{H}_{8}$ other than 1,3-pentadiene contribute individually to the yield in this channel only modestly as they require recyclization of 1-hexen-6-yl to cyclopentylmethyl radical followed by multiple isomerization reactions. The 1-buten-4-yl $\left(\mathrm{C}_{4} \mathrm{H}_{7}\right)$ fragment further undergoes spontaneous secondary dissociation via $\mathrm{H}$-atom loss to form 1,3-butadiene, as discussed in Section $\mathrm{V}$.

Despite the large size and cyclic structure of cyclohexyl, this radical appears to follow essentially the same mechanisms described for ethyl photodissociation and observed for the other alkyl radicals: passage through the conical intersection between the Rydberg $3 \mathrm{~s}$ and ground states leads to a significant number of impulsive $\mathrm{H}$-loss dissociation events, with the rest of the radicals dissociating from the hot ground state. The major difference here is that ground state cyclohexyl radicals are able to ring-open, and to access a variety of product channels not available to smaller radicals. Since cyclization does not affect the Rydberg states of the radical significantly and introduces no lower-lying valence states, the ultraviolet photochemistry in other cycloalkyl radicals should proceed similarly to cyclohexyl and the alkyl radicals in general.

\section{Conclusions}

Photoexcitation of cyclohexyl radical to the $3 \mathrm{p}$ Rydberg state at $248 \mathrm{~nm}$ leads to both excited state and ground state dissociation dynamics. Approximately $27 \%$ of radicals lose $\mathrm{H}$ atoms to form cyclohexene via a prompt, impulsive mechanism, likely following transfer from the $3 p$ to the $3 \mathrm{~s}$ Rydberg state and then passing through a conical intersection. The remaining $73 \%$ of radicals internally convert and dissociate with rates governed by statistical energy partitioning. The predominant channel remains H-loss to form cyclohexene $(\sim 36 \%)$, with other H-loss channels taken together representing $\sim 3 \%$. Dissociation to 1-buten4 -yl + ethene is an important channel at $\sim 33 \%$ of ground state dissociation, and the internally hot $\mathrm{C}_{4} \mathrm{H}_{7}$ fragment loses another $\mathrm{H}$ atom forming butadiene. The final $\sim 1 \%$ of experimentally observed ground-state dissociation occurs via the $\mathrm{C}_{5} \mathrm{H}_{8}+\mathrm{CH}_{3}$ channel, with 1,3-pentadiene as the predominant isomer. The branching to these channels is in excellent agreement with RRKM calculations, which also predict $\mathrm{C}_{4} \mathrm{H}_{6}+$ $\mathrm{C}_{2} \mathrm{H}_{5}$ and $\mathrm{C}_{3} \mathrm{H}_{6}+\mathrm{C}_{3} \mathrm{H}_{5}$ channels of comparable importance to methyl loss. If these latter two channels are active their signal levels were too low to be detected owing to a combination of low yield and unfavorable kinematics. Cyclohexyl is the largest alkyl radical and first cycloalkyl radical studied in this manner to date, yet seems to display essentially the same dissociation dynamics observed for all other smaller alkyl radicals.

\section{Supporting Information}

A range of forward convolution simulations to select TOF spectra demonstrating the need for a bimodal Hloss distribution. Theoretical RRKM product yield results as a function of available energy for cyclohexyl and 1-hexen-6-yl radicals. Extended ground-state potential energy diagram incorporating new isomerization and dissociation pathways. Geometries and frequencies of the new minima and transition state.

\section{Conflicts of Interest}

There are no conflicts to declare. 


\section{Acknowledgements}

This work was supported by the Director, Office of Basic Energy Sciences, Chemical Sciences, Geosciences, and Biosciences division of the U.S. Department of Energy under Contract DE-AC0205CH11231. We thank Dr. Hasan Celik and the UC Berkeley College of Chemistry NMR facility, with NMR instruments partially supported by NIH S10OD024998. Computational work was supported by NIH S10OD023532.

\section{Author Information Corresponding Author \\ *E-mail: dneumark@,berkeley.edu}

\section{References}

1. Kapur, G. S.; Singh, A. P.; Sarpal, A. S., Determination of aromatics and naphthenes in straight run gasoline by ${ }^{1}$ H NMR spectroscopy. Part I. Fuel 2000, 79, 1023-1029.

2. Hinrichs, J.; Shastry, V.; Junk, M.; Hemberger, Y.; Pitsch, H., An experimental and computational study on multicomponent evaporation of diesel fuel droplets. Fuel 2020, 275, 117727.

3. Atkinson, R.; Arey, J.; Aschmann, S. M., Atmospheric chemistry of alkanes: review and recent developments. Atmos. Environ. 2008, 42, 5859-5871.

4. Tzompa-Sosa, Z. A.; Henderson, B. H.; Keller, C. A.; Travis, K.; Mahieu, E.; Franco, B.; Estes, M.; Helmig, D.; Fried, A.; Richter, D.; Weibring, P.; Walega, J.; Blake, D. R.; Hannigan, J. W.; Ortega, I.; Conway, S.; Strong, K.; Fischer, E. V., Atmospheric implications of large $\mathrm{C}_{2}-\mathrm{C}_{5}$ alkane emissions from the US oil and gas industry. J. Geophys. Res. - Atmos. 2019, 124, 1148-1169.

5. Coustenis, A.; Salama, A.; Schulz, B.; Ott, S.; Lellouch, E.; Encrenaz, T.; Gautier, D.; Feuchtgruber, H., Titan's atmosphere from ISO mid-infrared spectroscopy. Icarus 2003, 161, 383-403.

6. Smith, G. P.; Nash, D., Local sensitivity analysis for observed hydrocarbons in a Jupiter photochemistry model. Icarus 2006, 182, 181-201.

7. $\quad$ Ashfold, M. N. R.; Ingle, R. A.; Karsili, T. N. V.; Zhang, J. S., Photoinduced C-H bond fission in prototypical organic molecules and radicals. Phys. Chem. Chem. Phys. 2019, 21, 13880-13901.

8. Giegerich, J.; Fischer, I., The photodissociation dynamics of alkyl radicals. J. Chem. Phys. 2015, $142,044304$.

9. Reisler, H.; Krylov, A. I., Interacting Rydberg and valence states in radicals and molecules: experimental and theoretical studies. Int. Rev. Phys. Chem. 2009, 28, 267-308.

10. Wendt, H. R.; Hunziker, H. E., The UV spectra of primary, secondary, and tertiary alkyl radicals. J. Chem. Phys. 1984, 81, 717-723.

11. North, S. W.; Blank, D. A.; Chu, P. M.; Lee, Y. T., Photodissociation dynamics of the methyl radical 3s Rydberg state. J. Chem. Phys. 1995, 102, 792-798.

12. Wu, G. R.; Jiang, B.; Ran, Q.; Zhang, J. H.; Harich, S. A.; Yang, X. M., Photodissociation dynamics of the methyl radical at $212.5 \mathrm{~nm}$ : effect of parent internal excitation. J. Chem. Phys. 2004, 120, 2193-2198. 13. Poullain, S. M.; Chicharro, D. V.; Zanchet, A.; González, M. G.; Rubio-Lago, L.; Senent, M. L.; García-Vela, A.; Bañares, L., Imaging the photodissociation dynamics of the methyl radical from the 3s and $3 \mathrm{p}_{z}$ Rydberg states. Phys. Chem. Chem. Phys. 2016, 18, 17054-17061.

14. Amaral, G.; Xu, K. S.; Zhang, J. S., UV photodissociation dynamics of ethyl radical via the $\tilde{\mathrm{A}}^{2} \mathrm{~A}^{\prime}$ (3s) state. J. Chem. Phys. 2001, 114, 5164-5169.

15. Steinbauer, M.; Giegerich, J.; Fischer, K. H.; Fischer, I., The photodissociation dynamics of the ethyl radical, $\mathrm{C}_{2} \mathrm{H}_{5}$, investigated by velocity map imaging. J. Chem. Phys. 2012, 137, 014303.

16. Chicharro, D. V.; Poullain, S. M.; Zanchet, A.; Bouallagui, A.; García-Vela, A.; Senent, M. L.; Rubio-Lago, L.; Bañares, L., Site-specific hydrogen-atom elimination in photoexcited ethyl radical. Chem. Sci. 2019, 10, 6494-6502. 
17. Poullain, S. M.; Chicharro, D. V.; Zanchet, A.; Rubio-Lago, L.; García-Vela, A.; Bañares, L., The $3 \mathrm{~s}$ versus $3 p$ Rydberg state photodissociation dynamics of the ethyl radical. Phys. Chem. Chem. Phys. 2019, 21, 23017-23025.

18. Knopp, G.; Beaud, P.; Radi, P.; Tulej, M.; Gerber, T., Femtosecond photodissociation of the ethyl radical $\mathrm{C}_{2} \mathrm{H}_{5}$. In Femtochemistry and Femtobiology: Ultrafast Dynamics in Molecular Science, Douhal, A., Ed. World Scientific: 2002; pp 116-120.

19. Song, Y.; Zheng, X. F.; Zhou, W. D.; Lucas, M.; Zhang, J. S., Ultraviolet photodissociation dynamics of the $n$-propyl and $i$-propyl radicals. J. Chem. Phys. 2015, 142, 224306.

20. Sun, G.; Zheng, X. F.; Song, Y.; Lucas, M.; Zhang, J. S., Ultraviolet photodissociation dynamics of the $n$-butyl, $s$-butyl, and $t$-butyl radicals. J. Chem. Phys. 2020, 152, 244303.

21. Sun, G.; Song, Y.; Zhang, J. S., Ultraviolet photodissociation dynamics of 1-pentyl radical. Chinese J. Chem. Phys. 2018, 31, 439-445.

22. Lucas, M., PhD Dissertation, University of California Riverside, 2016.

23. Negru, B.; Just, G. M. P.; Park, D.; Neumark, D. M., Photodissociation dynamics of the tert-butyl radical via photofragment translational spectroscopy at $248 \mathrm{~nm}$. Phys. Chem. Chem. Phys. 2011, 13, 81808185.

24. Sirjean, B.; Buda, F.; Hakka, H.; Glaude, P. A.; Fournet, R.; Warth, V.; Battin-Leclerc, F.; RuizLopèz, M., The autoignition of cyclopentane and cyclohexane in a shock tube. P. Combust. Inst. 2007, 31, 277-284.

25. Ji, C. S.; Dames, E.; Sirjean, B.; Wang, H.; Egolfopoulos, F. N., An experimental and modeling study of the propagation of cyclohexane and mono-alkylated cyclohexane flames. P. Combust. Inst. 2011, 33, 971-978.

26. Wang, Z.; Cheng, Z.; Yuan, W.; Cai, J.; Zhang, L.; Zhang, F.; Qi, F.; Wang, J., An experimental and kinetic modeling study of cyclohexane pyrolysis at low pressure. Combust. Flame 2012, 159, 22432253.

27. Stein, S. E.; Rabinovitch, B. S., Ring opening and isomerization of a series of chemically activated cycloalkyl radicals. J. Phys. Chem. 1975, 79, 191-198.

28. Gierczak, T.; Gawłowski, J.; Niedzielski, J., Isomerization of excited cyclohexyl, 1-hexen-6-yl and cyclopentylmethyl radicals. J. Photoch. Photobio. A 1990, 55, 25-35.

29. Houle, F. A.; Beauchamp, J. L., Thermal decomposition pathways of alkyl radicals by photoelectron spectroscopy. Application to cyclopentyl and cyclohexyl radicals. J. Phys. Chem. 1981, 85, 3456-3461.

30. Matheu, D. M.; Green, W. H.; Grenda, J. M., Capturing pressure-dependence in automated mechanism generation: reactions through cycloalkyl intermediates. Int. J. Chem. Kinet. 2003, 35, 95-119.

31. Zhang, H. Z. R.; Huynh, L. K.; Kungwan, N.; Yang, Z. W.; Zhang, S. W., Combustion modeling and kinetic rate calculations for a stoichiometric cyclohexane flame. 1. Major reaction pathways. $J$. Phys. Chem. A 2007, 111, 4102-4115.

32. Sirjean, B.; Glaude, P. A.; Ruiz-Lopèz, M. F.; Fournet, R., Theoretical kinetic study of thermal unimolecular decomposition of cyclic alkyl radicals. J. Phys. Chem. A 2008, 112, 11598-11610.

33. Goldsmith, C. F.; Ismail, H.; Green, W. H., Pressure and temperature dependence of the reaction of vinyl radical with alkenes III: measured rates and predicted product distributions for vinyl + butene. $J$. Phys. Chem. A 2009, 113, 13357-13371.

34. Gong, C. M.; Li, Z. R.; Li, X. Y., Theoretical kinetic study of thermal decomposition of cyclohexane. Energ. Fuel 2012, 26, 2811-2820.

35. Peukert, S.; Naumann, C.; Braun-Unkhoff, M.; Riedel, U., The reaction of cyclohexane with Hatoms: a shock tube and modeling study. Int. J. Chem. Kinet. 2012, 44, 130-146.

36. Fan, X. Y.; Wang, G. Q.; Li, Y.; Wang, Z. D.; Yuan, W. H.; Zhao, L., Experimental and kinetic modeling study of 1-hexene combustion at various pressures. Combust. Flame 2016, 173, 151-160.

37. Roberts, B. P.; Steel, A. J., Long-range proton hyperfine splittings in the EPR spectra of cyclohexyl and alkylcyclohexyl radicals: ring inversion in the cyclohexyl radical. J. Chem. Soc. Perk. T. 2 1992, 20252029.

38. Pottie, R. F.; Harrison, A. G.; Lossing, F. P., Free radicals by mass spectrometry. XXIV. Ionization potentials of cycloalkyl free radicals and cycloalkanes. J. Am. Chem. Soc. 1961, 83, 3204-3206. 
39. Platz, J.; Sehested, J.; Nielsen, O. J.; Wallington, T. J., Atmospheric chemistry of cyclohexane: UV spectra of $\mathrm{c}-\mathrm{C}_{6} \mathrm{H}_{11}{ }^{\circ}$ and $\left(\mathrm{c}-\mathrm{C}_{6} \mathrm{H}_{11}\right) \mathrm{O}_{2}{ }^{\circ}$ radicals, kinetics of the reactions of $\left(\mathrm{c}-\mathrm{C}_{6} \mathrm{H}_{11}\right) \mathrm{O}_{2}{ }^{*}$ radicals with NO and $\mathrm{NO}_{2}$, and the fate of the alkoxy radical $\left(\mathrm{c}-\mathrm{C}_{6} \mathrm{H}_{11}\right) \mathrm{O}^{\circ}$. J. Phys. Chem. A 1999, 103, 2688-2695.

40. $\quad$ Noyes, W. A., $n$-Butyl nitrite. Org. Synth. 1936, 16, 7-8.

41. Lee, Y. T.; Mcdonald, J. D.; Lebreton, P. R.; Herschbach, D. R., Molecular beam reactive scattering apparatus with electron bombardment detector. Rev. Sci. Instrum. 1969, 40, 1402-1408.

42. Negru, B.; Goncher, S. J.; Brunsvold, A. L.; Just, G. M. P.; Park, D.; Neumark, D. M., Photodissociation dynamics of the phenyl radical via photofragment translational spectroscopy. J. Chem. Phys. 2010, 133, 074302.

43. Kohn, D. W.; Clauberg, H.; Chen, P., Flash pyrolysis nozzle for generation of radicals in a supersonic jet expansion. Rev. Sci. Instrum. 1992, 63, 4003-4005.

44. Kuhnke, K.; Kern, K.; David, R.; Comsa, G., High efficiency molecular-beam ionization detector with short ionization region. Rev. Sci. Instrum. 1994, 65, 3458-3465.

45. Daly, N. R., Scintillation type mass spectrometer ion detector. Rev. Sci. Instrum. 1960, 31, 264267.

46. Casavecchia, P.; Leonori, F.; Balucani, N.; Petrucci, R.; Capozza, G.; Segoloni, E., Probing the dynamics of polyatomic multichannel elementary reactions by crossed molecular beam experiments with soft electron-ionization mass spectrometric detection. Phys. Chem. Chem. Phys. 2009, 11, 46-65.

47. Shapero, M.; Cole-Filipiak, N. C.; Haibach-Morris, C.; Neumark, D. M., Benzyl radical photodissociation dynamics at $248 \mathrm{~nm}$. J. Phys. Chem. A 2015, 119, 12349-12356.

48. Harich, S. A., PHOTRAN, a program for forward convolution analysis of photodissociation, 2003. 49. Chai, J.-D.; Head-Gordon, M., Long-range corrected hybrid density functionals with damped atomatom dispersion corrections. Phys. Chem. Chem. Phys. 2008, 10, 6615-6620.

50. Dunning, T. H., Gaussian basis sets for use in correlated molecular calculations. I. The atoms boron through neon and hydrogen. J. Chem. Phys. 1989, 90, 1007-1023.

51. Kendall, R. A.; Dunning, T. H.; Harrison, R. J., Electron affinities of the first-row atoms revisited. Systematic basis sets and wave functions. J. Chem. Phys. 1992, 96, 6796-6806.

52. Frisch, M. J., Trucks, G. W., Schlegel, H. B., Scuseria, G. E., Robb, M. A., Cheeseman, J. R., Scalmani, G., Barone, V., Petersson, G. A., Nakatsuji, H., Li, X., Caricato, M., Marenich, A. V., Bloino, J., Janesko, B. G., Gomperts, R., Mennucci, B., Hratchian, H. P., Ortiz, J. V., Izmaylov, A. F., Sonnenberg, J. L., Williams-Young, D., Ding, F., Lipparini, F., Egidi, F., Goings, J., Peng, B., Petrone, A., Henderson, T., Ranasinghe, D., Zakrzewski, V. G., Gao, J., Rega, N., Zheng, G., Liang, W., Hada, M., Ehara, M., Toyota, K., Fukuda, R., Hasegawa, J., Ishida, M., Nakajima, T., Honda, Y., Kitao, O., Nakai, H., Vreven, T., Throssell, K., Montgomery, J. A., Jr., Peralta, J. E., Ogliaro, F., Bearpark, M. J., Heyd, J. J., Brothers, E. N., Kudin, K. N., Staroverov, V. N., Keith, T. A., Kobayashi, R., Normand, J., Raghavachari, K., Rendell, A. P., Burant, J. C., Iyengar, S. S., Tomasi, J., Cossi, M., Millam, J. M., Klene, M., Adamo, C., Cammi, R., Ochterski, J. W., Martin, R. L., Morokuma, K., Farkas, O., Foresman, J. B., Fox, D. J. Gaussian 16, Rev. A.03, Gaussian, Inc.: Wallingford, CT, 2016.

53. Stanton, J. F.; Bartlett, R. J., The equation of motion coupled-cluster method. A systematic biorthogonal approach to molecular excitation energies, transition probabilities, and excited state properties. J. Chem. Phys. 1993, 98, 7029-7039.

54. Marcus, R. A.; Rice, O. K., The kinetics of the recombination of methyl radicals and iodine atoms. J. Phys. Colloid Chem. 1951, 55, 894-908.

55. Karas, A. J.; Gilbert, R. G.; Collins, M. A., Rigorous derivation of reaction path degeneracy in transition state theory. Chem. Phys. Lett. 1992, 193, 181-184.

56. Astholz, D. C.; Troe, J.; Wieters, W., Unimolecular processes in vibrationally highly excited cycloheptatrienes. I. Thermal isomerization in shock waves. J. Chem. Phys. 1979, 70, 5107-5116.

57. Gilbert, R. G.; Smith, S. C., Theory of unimolecular and recombination reactions. Blackwell Scientific Publications: Oxford, UK, 1990.

58. Beyer, T.; Swinehart, D. F., Algorithm 448, Number of multiply-restricted partitions. Commun. ACM 1973, 16, 379-379.

59. Das, R. C.; Koga, O.; Suzuki, S., Chemical ionization mass spectrometry of alkyl nitrates and nitrites. B. Chem. Soc. Japan 1979, 52, 65-68.

60. Effenhauser, C. S.; Felder, P.; Huber, J. R., Photodissociation of alkyl nitrites in a molecular beam. Primary and secondary reactions. J. Phys. Chem. 1990, 94, 296-302. 
61. Heinemann-Fiedler, P.; Hoyermann, K.; Rohde, G., The reactions of the cyclic hydrocarbon radicals c- $\mathrm{C}_{3} \mathrm{H}_{5}, \mathrm{c}-\mathrm{C}_{5} \mathrm{H}_{9}$, and $\mathrm{c}-\mathrm{C}_{6} \mathrm{H}_{11}$ with $\mathrm{O}$ atoms in the gas phase. Ber. Bunsen. Phys. Chem. 1990, 94, 1400-1404.

62. Rohrs, H. W.; Wickham-Jones, C. T.; Ellison, G. B.; Berry, D.; Argrow, B. M., Fourier transform infrared absorption spectroscopy of jet-cooled radicals. Rev. Sci. Instrum. 1995, 66, 2430-2441.

63. Cole-Filipiak, N. C.; Shapero, M.; Negru, B.; Neumark, D. M., Revisiting the photodissociation dynamics of the phenyl radical. J. Chem. Phys. 2014, 141, 104307.

64. Hernandez-Castillo, A. O.; Abeysekera, C.; Stanton, J. F.; Zwier, T. S., Structural characterization of phenoxy radical with mass-correlated broadband microwave spectroscopy. J. Phys. Chem. Lett. 2019, 10, 2919-2923.

65. Zare, R. N., Photoejection dynamics. Mol. Photochem. 1972, 4, 1-37.

66. Fitch, W. L.; Sauter, A. D., Calculation of relative electron impact total ionization cross-sections for organic molecules. Anal. Chem. 1983, 55, 832-835.

67. Stein, S. E., director, NIST Mass Spec Data Center, "Mass Spectra" in NIST Chemistry WebBook, NIST Standard Reference Database Number 69, Eds. P.J. Linstrom and W.G. Mallard, National Institute of Standards and Technology, Gaithersburg, MD, 20899, http://webbook.nist.gov, (retrieved January 21, 2021).

68. Yamashita, S., Mass spectrometric study of the primary processes in photochemical reactions. II. Mass spectra of methyl and ethyl radicals. B. Chem. Soc. Japan 1974, 47, 1373-1374.

69. Jiao, C. Q.; Adams, S. F., Electron ionization of cyclohexene. J. Phys. B: At. Mol. Opt. Phys. 2014, 47, 225203.

70. Li, Y.; Klippenstein, S. J.; Zhou, C. W.; Curran, H. J., Theoretical kinetics analysis for $\dot{H}$ atom addition to 1,3-butadiene and related reactions on the $\dot{\mathrm{C}}_{4} \mathrm{H}_{7}$ potential energy surface. J. Phys. Chem. A 2017, $121,7433-7445$.

71. Klots, C. E., Thermochemical and kinetic information from metastable decompositions of ions. $J$. Chem. Phys. 1973, 58, 5364-5367.

72. Yu, C. F.; Youngs, F.; Bersohn, R.; Turro, N. J., Photodissociation at $193 \mathrm{~nm}$ of cyclooctatetraene and styrene into benzene and acetylene. J. Phys. Chem. 1985, 89, 4409-4412.

73. Baer, T.; Hase, W. L., Unimolecular Reaction Dynamics: Theory and Experiments. Oxford University Press: New York, USA, 1996.

74. Evleth, E. M.; Cao, H. Z.; Kassab, E.; Sevin, A., Computation of the direct adiabatic channel for the relaxation of electronically excited $\mathrm{C}_{2} \mathrm{H}_{5}$ radical to give $\mathrm{H}+\mathrm{C}_{2} \mathrm{H}_{4}$. Chem. Phys. Lett. 1984, 109, 45-49.

75. Matsika, S.; Yarkony, D. R., Accidental conical intersections of three states of the same symmetry. I. Location and relevance. J. Chem. Phys. 2002, 117, 6907-6910.

76. Chicharro, D. V.; Zanchet, A.; Bouallagui, A.; Rubio-Lago, L.; García-Vela, A.; Bañares, L.; Poullain, S. M., Site-specific hydrogen-atom elimination in photoexcited alkyl radicals. Phys. Chem. Chem. Phys. 2021, 23, 2458-2468.

77. Min, Z. Y.; Quandt, R.; Bersohn, R., Kinetic energies of hydrogen atoms photodissociated from alkyl radicals. Chem. Phys. Lett. 1998, 296, 372-376. 


\section{Supporting Information}

\section{Multi-component simulations of $\mathrm{C}_{6} \mathrm{H}_{10}$ TOF spectra}

Representative TOF spectra collected for $m / z=81\left(\mathrm{C}_{6} \mathrm{H}_{9}{ }^{+}\right)$are shown in Figure $\mathrm{S} 1$, and several unique simulations to this data are included. If only the 'fast' component is included (purple lines) it is not possible to adequately simulate ion signal at long arrival times. In order to simulate these TOF spectra it is necessary to include a 'slow' component in the distribution. The simulated spectra are weakly dependent on the amount of the slow component under the present experimental conditions. The shaded areas display the range of acceptable simulations to the global dataset, corresponding to a slow-component weighting of $0.30-0.75$ of the total simulation. The best agreement between experimental and simulated TOF data is found when 0.6 is used as the slow-component weighting (black lines).

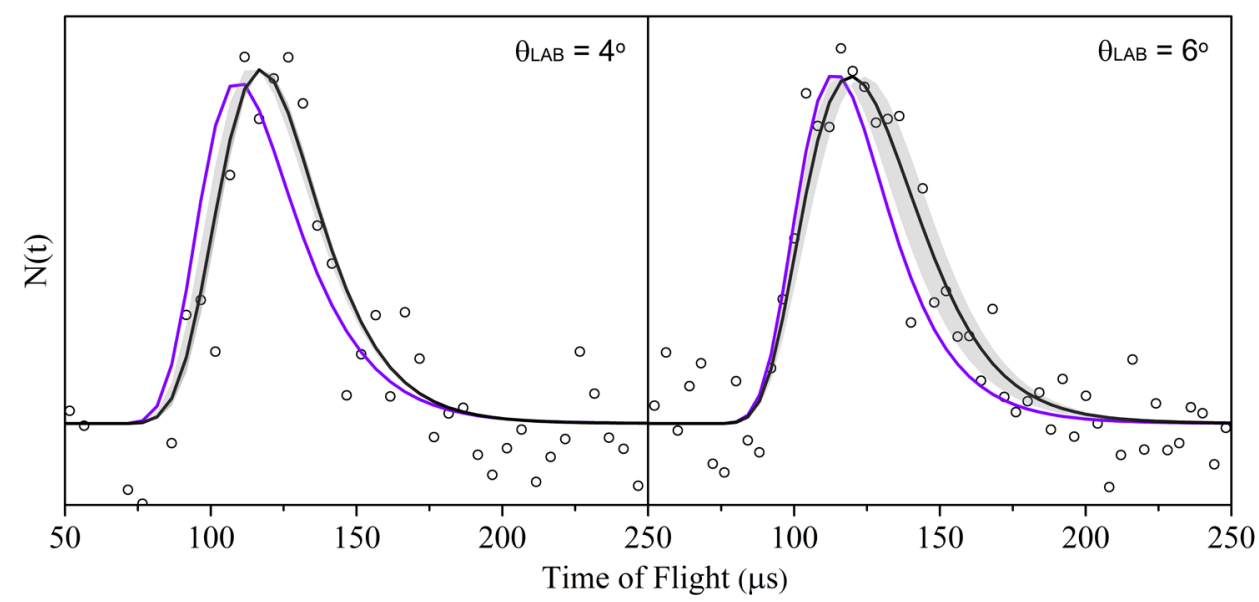

Figure S1. TOF spectra of $m / z=81\left(\mathrm{C}_{6} \mathrm{H}_{9}{ }^{+}\right)$showing different simulations achieved by varying the weighting of the fast and slow components of the $\mathrm{P}\left(\mathrm{E}_{\mathrm{T}}\right)$.

\section{RRKM branching ratios for cyclohexyl and 1-hexen-6-yl radicals}

The RRKM product branching was evaluated as a function of available energy for cyclohexyl radical, as well as 1-hexen-6-yl which could potentially be formed by ring-opening of cyclohexyl radical inside the pyrolysis source. The relative yields of different product channels for these two species are compared in Figure S2. The available energy for absorption of a single $248 \mathrm{~nm}$ photon is $115.3 \mathrm{kcal} / \mathrm{mol}\left(40,327 \mathrm{~cm}^{-1}\right)$ assuming radicals internally convert to their ground electronic states.

For cyclohexyl radicals, $\mathrm{H}$-atom loss is almost always the dominant channel. Of the 9 different $\mathrm{H}$-loss pathways considered, cyclohexene represents the overwhelming majority of this channel over the entire range of energies. While the $\mathrm{C}_{4} \mathrm{H}_{7}+\mathrm{C}_{2} \mathrm{H}_{4}$ channel accounts for slightly less of overall dissociation for the photon energy used in the experiment, it actually accounts for the greatest fraction of dissociation from $\sim 26,000-34,000 \mathrm{~cm}^{-1}$. This channel peaks in importance at $30,800 \mathrm{~cm}^{-1}$ with $49 \%$ of total dissociation and then gradually decreases for higher energies. The other channels all peak in importance at around 20,000 $\mathrm{cm}^{-1}$ before decreasing to very low percentage yields. The maximum predicted yields of $\mathrm{C}_{5} \mathrm{H}_{8}+\mathrm{CH}_{3}, \mathrm{C}_{4} \mathrm{H}_{6}$ $+\mathrm{C}_{2} \mathrm{H}_{5}$, and $\mathrm{C}_{3} \mathrm{H}_{6}+\mathrm{C}_{3} \mathrm{H}_{5}$ are about $12 \%, 26 \%$ and $10 \%$ respectively. 
If 1-hexen-6-yl were formed instead, the RRKM product branching differs dramatically compared to cyclohexyl radicals. Once the available energy is high enough to make other product channels accessible, $\mathrm{H}$-atom loss channels decrease enormously in importance, falling to a low of only $3 \%$ at $30,000 \mathrm{~cm}^{-1}$. For much higher available energies their relative importance starts to increase again, with only 1,5-hexadiene and 4-methyl-1,3-pentadiene isomers carrying any real importance. $\mathrm{The}_{5} \mathrm{C}_{5} \mathrm{H}_{8}+\mathrm{CH}_{3}, \mathrm{C}_{4} \mathrm{H}_{6}+\mathrm{C}_{2} \mathrm{H}_{5}$, and $\mathrm{C}_{3} \mathrm{H}_{6}+\mathrm{C}_{3} \mathrm{H}_{5}$ channels again achieve peak yields for $\sim 20,000 \mathrm{~cm}^{-1}$ before decreasing to negligible levels. Maximum yields for these channels are in this case about $16 \%, 37 \%$ and $13 \%$ respectively. Of particular importance to this experiment is the very large branching to $\mathrm{C}_{4} \mathrm{H}_{7}+\mathrm{C}_{2} \mathrm{H}_{4}$, responsible for the greatest yield of any channel over almost the full energy range. At the available energy relevant to this experiment, the theoretical $\left(\mathrm{C}_{4} \mathrm{H}_{7}+\mathrm{C}_{2} \mathrm{H}_{4}\right) /\left(\mathrm{C}_{6} \mathrm{H}_{10}+\mathrm{H}\right)$ channel ratio is 10.2 , compared to the values of 0.80 for cyclohexyl RRKM and $0.86_{-0.07}^{+0.10}$ found experimentally.

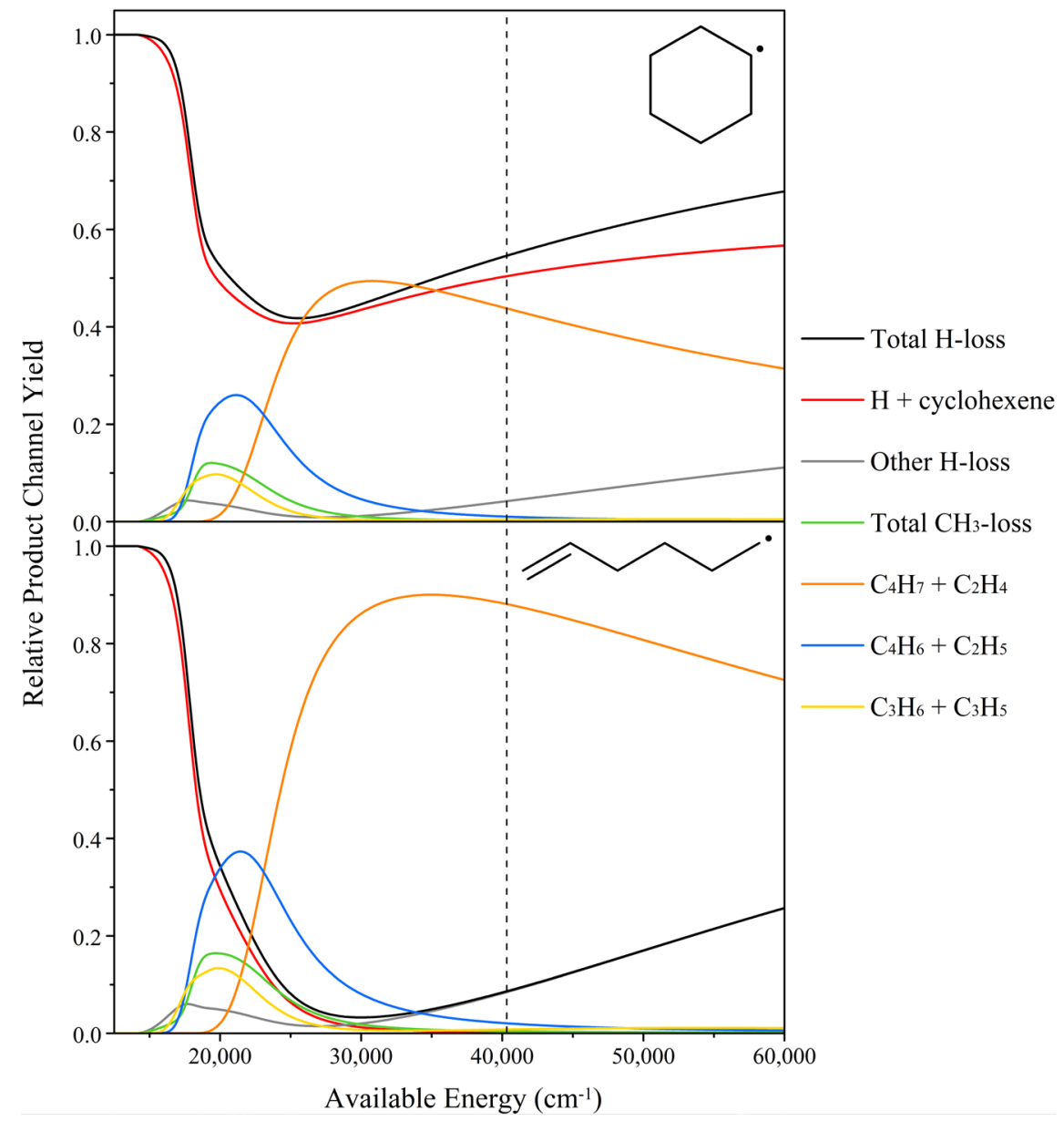

Figure S2. RRKM product branching as a function of available energy starting from cyclohexyl radical (top) and 1-hexen-6-yl radical (bottom). The vertical dashed line shows the energy contained in a single $248 \mathrm{~nm}$ photon.

\section{Extended potential energy diagram}

Isomerization and dissociation channels not previously considered for cyclohexyl radical were calculated using DFT at the $\omega$ B97X-D/aug-cc-PVTZ level of theory. These calculations produced the W8W10 minima and TS19-TS36 transition states shown in Figures S3-S4. Energies are reported in units of $\mathrm{kcal} / \mathrm{mol}$ relative to cyclohexyl radical, including zero-point corrections, and ring-opening of cyclohexyl is the first step required to access all isomers in these diagrams. Where these are connected to parts of the potential energy diagram from Gong et al., ${ }^{1}$ those authors nomenclature of W1-W7 is used. See Gong et al. for connectivity amongst W1-W7, which are not reproduced here. 


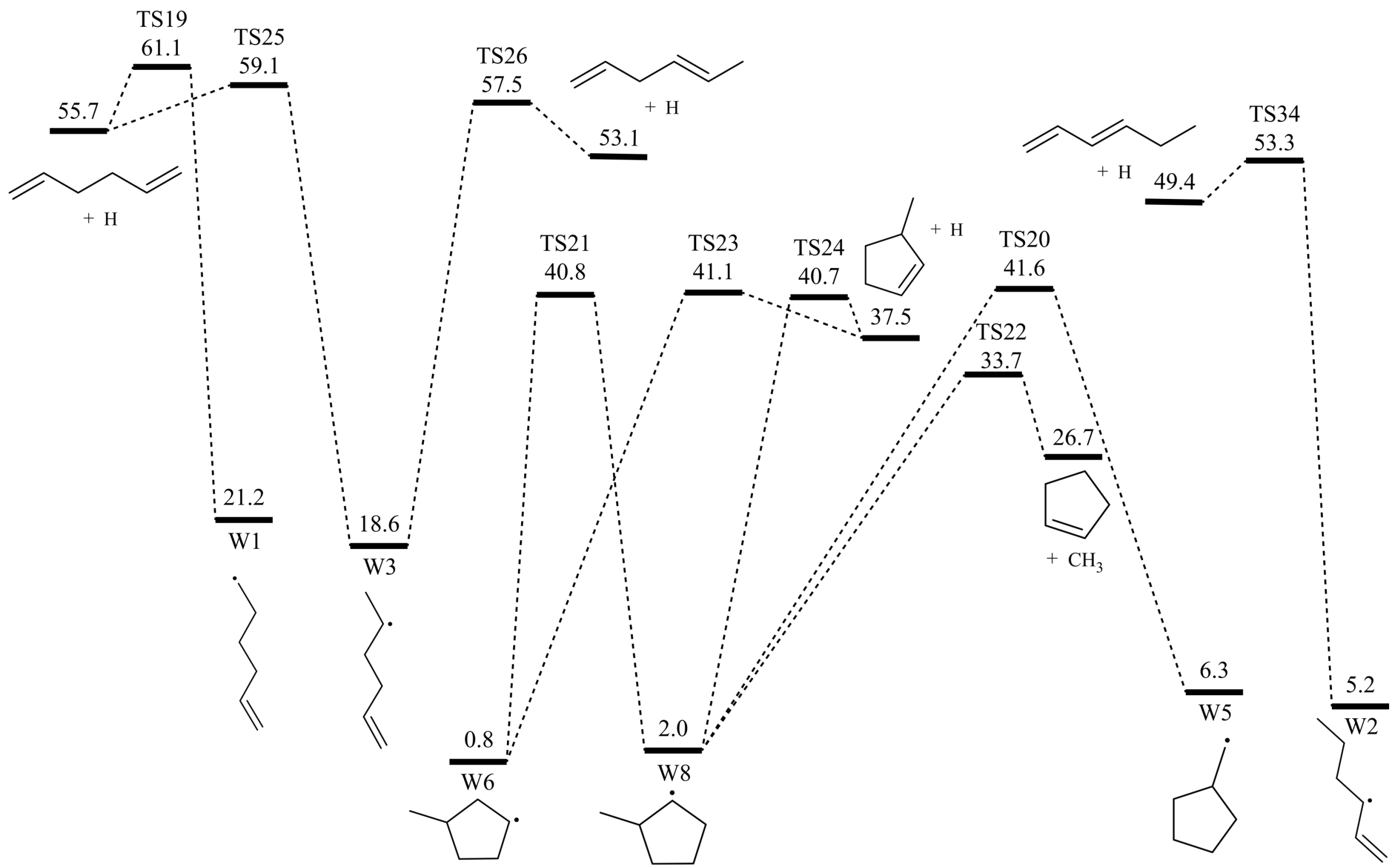

Figure S3. Extended potential energy diagram showing additional isomerization and dissociation pathways available to ground-state $\mathrm{C}_{6} \mathrm{H}_{11}$ radicals $($ part 1 ). 


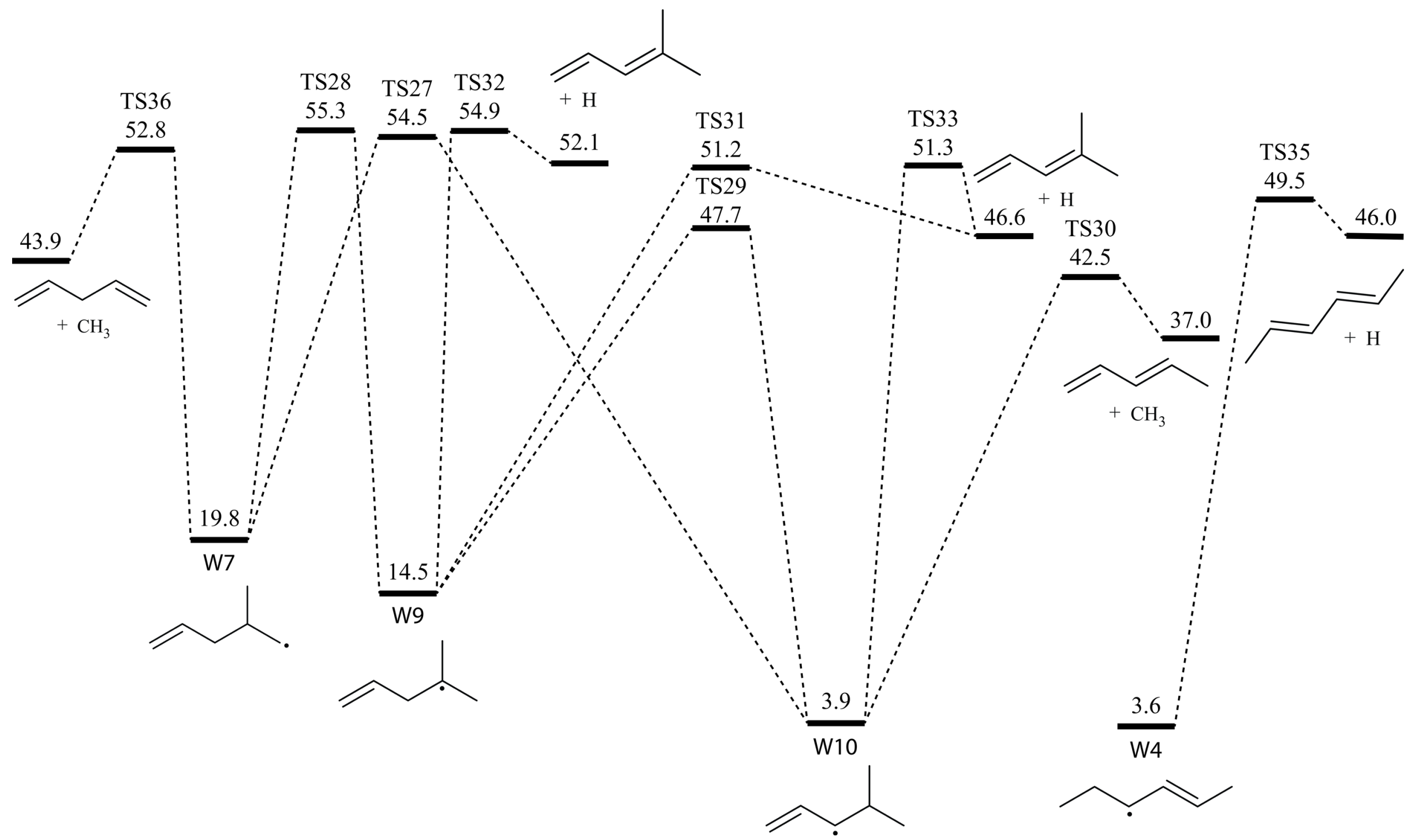

Figure S4. Extended potential energy diagram showing additional isomerization and dissociation pathways available to ground-state $\mathrm{C}_{6} \mathrm{H}_{11}$ radicals (part 2). 


\section{Stationary point geometries and vibrational frequencies from DFT calculations}

The results of the DFT calculations for species relevant to this work are included below. Frequencies are in units of $\mathrm{cm}^{-1}$ and the molecular geometries use units of $\AA$.

Minima:

W8 (1-methylcyclopenten-2-yl // 1- $\left.\mathrm{CH}_{3}-\mathrm{C}_{5} \mathrm{H}_{8}-2\right)$ :

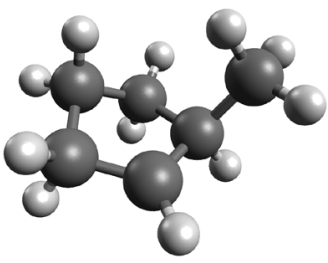

Frequencies:

$118,212,244,302,374$, $436,591,710,797,850$, $890,907,934,980,1003$, $1028,1056,1059,1100$, $1187,1211,1251,1292$, $1312,1337,1337,1362$, $1376,1410,1476,1494$, $1500,1506,1515,2970$, $3021,3038,3053,3056$, $3066,3104,3111,3117$, 3120,3210

\begin{tabular}{rrrr}
\multicolumn{4}{c}{ Geometry } \\
\hline $\mathrm{C}$ & 1.2213950000 & -0.7715810000 & 0.4564670000 \\
$\mathrm{C}$ & 1.4806680000 & 0.7117910000 & 0.1497860000 \\
$\mathrm{C}$ & -0.8239150000 & 0.1041870000 & -0.5268730000 \\
$\mathrm{H}$ & 2.1032640000 & -1.3964570000 & 0.3230210000 \\
$\mathrm{H}$ & 0.8975820000 & -0.8800710000 & 1.4934290000 \\
$\mathrm{H}$ & 2.2158480000 & 0.8097340000 & -0.6616870000 \\
$\mathrm{H}$ & -1.3009930000 & 0.2097090000 & -1.5064090000 \\
$\mathrm{C}$ & 0.0775410000 & -1.1462480000 & -0.4916580000 \\
$\mathrm{H}$ & -0.4599920000 & -2.0409470000 & -0.1769710000 \\
$\mathrm{H}$ & 0.4784760000 & -1.3364690000 & -1.4894080000 \\
$\mathrm{C}$ & -1.9421290000 & 0.0525040000 & 0.5255760000 \\
$\mathrm{H}$ & -2.6406300000 & -0.7570150000 & 0.3061240000 \\
$\mathrm{H}$ & -1.5303670000 & -0.1129330000 & 1.5226010000 \\
$\mathrm{H}$ & -2.5010190000 & 0.9883950000 & 0.5472250000 \\
$\mathrm{C}$ & 0.1443950000 & 1.2154680000 & -0.2763960000 \\
$\mathrm{H}$ & 1.8966710000 & 1.2577120000 & 0.9999610000 \\
$\mathrm{H}$ & -0.1065730000 & 2.2616130000 & -0.3793070000
\end{tabular}

W9 (4-methylpent-1-en-4-yl // 4- $\mathrm{CH}_{3}-1-\mathrm{C}_{5} \mathrm{H}_{8}-4$ ):

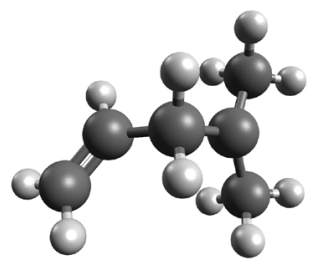

Frequencies:

$51,82,114,121,189,346$, $367,405,458,656,792$, 914, 927, 946, 962, 995, $1015,1044,1056,1094$, $1220,1282,1322,1334$, $1341,1406,1419,1456$, $1473,1477,1482,1491$, $1498,1724,2963,2975$, 3026, 3060, 3061, 3075, $3107,3109,3143,3156$, 3234

\begin{tabular}{rrrr}
\multicolumn{4}{c}{ Geometry } \\
\hline $\mathrm{C}$ & 0.3372320000 & -0.4030790000 & 0.8560240000 \\
$\mathrm{H}$ & 0.1922130000 & -1.3672400000 & 1.3518970000 \\
$\mathrm{H}$ & 0.6905030000 & 0.3059190000 & 1.6096170000 \\
$\mathrm{C}$ & -1.0843510000 & 1.4971710000 & -0.1162560000 \\
$\mathrm{H}$ & -2.1292980000 & 1.8023910000 & -0.1953230000 \\
$\mathrm{H}$ & -0.5861740000 & 2.1525380000 & 0.6006740000 \\
$\mathrm{H}$ & -0.6200040000 & 1.6913310000 & -1.0937840000 \\
$\mathrm{C}$ & 1.3960000000 & -0.5505250000 & -0.2071640000 \\
$\mathrm{H}$ & 1.2103920000 & -1.3145530000 & -0.9563680000 \\
$\mathrm{C}$ & 2.4812750000 & 0.2013620000 & -0.3055130000 \\
$\mathrm{H}$ & 2.6970520000 & 0.9765320000 & 0.4208010000 \\
$\mathrm{H}$ & 3.1928000000 & 0.0675930000 & -1.1093270000 \\
$\mathrm{C}$ & -0.9619550000 & 0.0656330000 & 0.2733140000 \\
$\mathrm{H}$ & -1.5796240000 & -1.1798320000 & -1.3732680000 \\
$\mathrm{C}$ & -1.8800650000 & -0.9303640000 & -0.3446010000 \\
$\mathrm{H}$ & -2.9011370000 & -0.5488920000 & -0.4054790000 \\
$\mathrm{H}$ & -1.8955360000 & -1.8669750000 & 0.2157390000
\end{tabular}


W10 (4-methylpent-2-en-3-yl // 4- $\left.\mathrm{CH}_{3}-1-\mathrm{C}_{5} \mathrm{H}_{8}-3\right)$ :

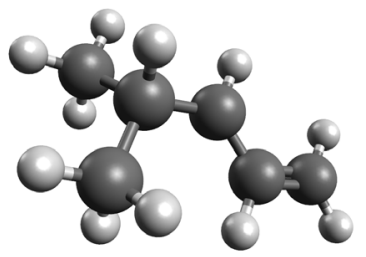

Frequencies:

84, 163, 209, 245, 295, $348,406,432,549,582$, $775,812,827,930,945$, 978, 1008, 1038, 1091, $1143,1198,1222,1303$, $1325,1349,1374,1407$, 1427, 1494, 1498, 1510, $1510,1520,1533,2996$, 3040, 3044, 3113, 3117, $3119,3123,3141,3157$, 3169,3257

\section{Transition States:}

TS19:

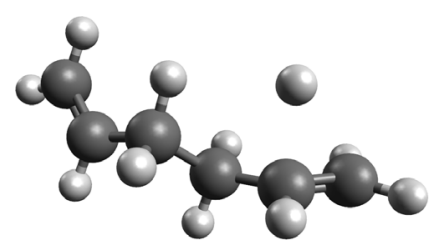

Frequencies:

718i, 69, 87, 111, 197, $350,379,419,463,477$, $614,662,790,932,938$, 957, 966, 974, 1042, 1046, 1064, 1104, 1183, 1253, $1283,1313,1323,1340$, $1380,1460,1462,1481$, 1495, 1653, 1736, 3027, 3034, 3080, 3098, 3139, 3149, 3152, 3156, 3237, 3247
Geometry

\begin{tabular}{rrrr}
\hline $\mathrm{C}$ & 0.4207980000 & -0.4717700000 & -0.3522140000 \\
$\mathrm{H}$ & -1.3222960000 & -0.1302480000 & -1.4683120000 \\
$\mathrm{H}$ & 0.6272300000 & -1.4858840000 & -0.6838890000 \\
$\mathrm{C}$ & -1.2725350000 & 1.3803100000 & 0.0348010000 \\
$\mathrm{H}$ & -1.0073590000 & 1.5130400000 & 1.0856570000 \\
$\mathrm{H}$ & -0.7001600000 & 2.0983190000 & -0.5528760000 \\
$\mathrm{H}$ & -2.3292380000 & 1.6252390000 & -0.0734590000 \\
$\mathrm{C}$ & 1.4857750000 & 0.2823130000 & 0.0929230000 \\
$\mathrm{H}$ & 1.2923940000 & 1.2953660000 & 0.4293210000 \\
$\mathrm{C}$ & 2.7900470000 & -0.1620010000 & 0.1414140000 \\
$\mathrm{H}$ & 3.0509680000 & -1.1622910000 & -0.1792190000 \\
$\mathrm{H}$ & 3.5865790000 & 0.4728980000 & 0.5000650000 \\
$\mathrm{C}$ & -1.0155950000 & -0.0523800000 & -0.4175540000 \\
$\mathrm{H}$ & -2.9454330000 & -0.7999340000 & 0.2506730000 \\
$\mathrm{C}$ & -1.8877330000 & -1.0381310000 & 0.3712050000 \\
$\mathrm{H}$ & -1.6466380000 & -0.9934240000 & 1.4347010000 \\
$\mathrm{H}$ & -1.7305900000 & -2.0631360000 & 0.0338860000
\end{tabular}

Geometry

\begin{tabular}{rrrr}
\hline $\mathrm{C}$ & 2.9456150000 & -0.2610330000 & 0.4651680000 \\
$\mathrm{C}$ & 1.9687420000 & -0.0149680000 & -0.3933920000 \\
$\mathrm{H}$ & 2.8468440000 & -0.0169230000 & 1.5164480000 \\
$\mathrm{H}$ & 3.8775110000 & -0.7100810000 & 0.1491860000 \\
$\mathrm{H}$ & 2.1080780000 & -0.2780590000 & -1.4388110000 \\
$\mathrm{C}$ & 0.6480260000 & 0.5940920000 & -0.0414940000 \\
$\mathrm{C}$ & -0.5214640000 & -0.3447560000 & -0.3516730000 \\
$\mathrm{H}$ & 0.5130440000 & 1.5206190000 & -0.6084620000 \\
$\mathrm{H}$ & 0.6296580000 & 0.8669390000 & 1.0150590000 \\
$\mathrm{C}$ & -1.8798850000 & 0.2717080000 & -0.1831380000 \\
$\mathrm{H}$ & -0.4356520000 & -0.6682790000 & -1.3946510000 \\
$\mathrm{H}$ & -0.4434250000 & -1.2459690000 & 0.2589850000 \\
$\mathrm{C}$ & -2.9488390000 & -0.3823690000 & 0.2909120000 \\
$\mathrm{H}$ & -1.5557040000 & 1.4198660000 & 1.4263970000 \\
$\mathrm{H}$ & -2.0278440000 & 1.2352790000 & -0.6614470000 \\
$\mathrm{H}$ & -3.9282820000 & 0.0747670000 & 0.3030960000 \\
$\mathrm{H}$ & -2.8573950000 & -1.3742020000 & 0.7159020000
\end{tabular}


TS20:

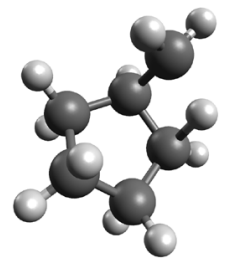

Frequencies:

2116i, 172, 245, 376, 387, $569,587,676,819,848$, $875,896,909,929,947$, 981, 1004, 1035, 1083, $1125,1177,1211,1214$, $1275,1283,1319,1341$, 1345, 1354, 1366, 1430, 1488, 1498, 1515, 1809, 3011, 3052, 3060, 3098, $3102,3105,3111,3120$, 3156,3206
Geometry

\begin{tabular}{rrrr}
\hline $\mathrm{C}$ & 1.2658090000 & -0.5915570000 & 0.5029200000 \\
$\mathrm{C}$ & 1.2825410000 & 0.8801690000 & 0.0747150000 \\
$\mathrm{C}$ & -0.8582740000 & -0.1688450000 & -0.5914940000 \\
$\mathrm{H}$ & 2.2447580000 & -1.0640030000 & 0.4388090000 \\
$\mathrm{H}$ & 0.9324550000 & -0.6688560000 & 1.5398420000 \\
$\mathrm{H}$ & 1.9181910000 & 1.0007560000 & -0.8102670000 \\
$\mathrm{H}$ & -1.3791510000 & -0.2382390000 & -1.5434970000 \\
$\mathrm{C}$ & 0.2332810000 & -1.2315610000 & -0.4329200000 \\
$\mathrm{H}$ & -0.1551550000 & -2.1776970000 & -0.0556800000 \\
$\mathrm{H}$ & 0.6940350000 & -1.4280180000 & -1.4036040000 \\
$\mathrm{C}$ & -1.7794450000 & -0.0115270000 & 0.6122880000 \\
$\mathrm{H}$ & -1.6760250000 & -0.7183930000 & 1.4311360000 \\
$\mathrm{H}$ & -0.9964710000 & 1.1292750000 & 0.8095870000 \\
$\mathrm{H}$ & -2.7928640000 & 0.3215460000 & 0.4162290000 \\
$\mathrm{C}$ & -0.1537670000 & 1.1658160000 & -0.2956270000 \\
$\mathrm{H}$ & 1.6734220000 & 1.5465470000 & 0.8428310000 \\
$\mathrm{H}$ & -0.4040650000 & 2.0421180000 & -0.8846790000
\end{tabular}

TS21:

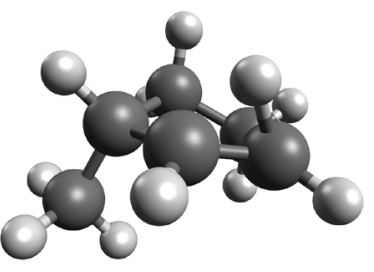

Frequencies:

1887i, 166, 233, 256, 371, 412, 578, 668, 689, 791, 813, 879, 909, 941, 970, 998, 1042, 1051, 1110, $1115,1194,1214,1265$, 1287, 1303, 1320, 1346, 1361, 1376, 1411, 1492, $1499,1508,1512,2213$, 3006, 3038, 3053, 3066, 3095, 3110, 3114, 3118, 3198,3215
Geometry

\begin{tabular}{rrrr}
\hline $\mathrm{C}$ & -1.2689550000 & -0.7429820000 & -0.4441480000 \\
$\mathrm{C}$ & -1.3775480000 & 0.7434730000 & -0.2602180000 \\
$\mathrm{C}$ & 0.8218970000 & 0.0618190000 & 0.5417950000 \\
$\mathrm{H}$ & -2.1947000000 & -1.2839000000 & -0.2496360000 \\
$\mathrm{H}$ & -0.9769410000 & -0.9684480000 & -1.4765640000 \\
$\mathrm{H}$ & -1.2327290000 & 1.0944770000 & 0.9814950000 \\
$\mathrm{H}$ & 1.3560210000 & 0.1091320000 & 1.4923430000 \\
$\mathrm{C}$ & -0.1418230000 & -1.1415710000 & 0.5231270000 \\
$\mathrm{H}$ & 0.3562840000 & -2.0655840000 & 0.2321330000 \\
$\mathrm{H}$ & -0.5581240000 & -1.2899080000 & 1.5216750000 \\
$\mathrm{C}$ & 1.8531700000 & -0.0121730000 & -0.5886240000 \\
$\mathrm{H}$ & 2.5010930000 & -0.8819840000 & -0.4644020000 \\
$\mathrm{H}$ & 1.3630330000 & -0.0899710000 & -1.5607330000 \\
$\mathrm{H}$ & 2.4816750000 & 0.8787210000 & -0.6040620000 \\
$\mathrm{C}$ & -0.1048330000 & 1.2343180000 & 0.3511340000 \\
$\mathrm{H}$ & -2.0201070000 & 1.3862960000 & -0.8430050000 \\
$\mathrm{H}$ & 0.2330510000 & 2.2538640000 & 0.2323620000
\end{tabular}




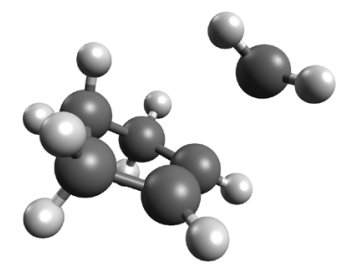

Frequencies:

516i, 114, 135, 156, 225, 381, 508, 533, 619, 726, $782,819,844,893,921$, 932, 956, 981, 1047, 1066, 1116, 1150, 1229, 1244, 1317, 1332, 1337, 1385, 1424, 1429, 1487, 1497, 1516, 1545, 3019, 3035, $3063,3076,3100,3105$, $3124,3200,3220,3258$, 3265

Geometry

\begin{tabular}{rrrr}
\hline $\mathrm{C}$ & 1.2658090000 & -0.5915570000 & 0.5029200000 \\
$\mathrm{C}$ & 1.2825410000 & 0.8801690000 & 0.0747150000 \\
$\mathrm{C}$ & -0.8582740000 & -0.1688450000 & -0.5914940000 \\
$\mathrm{H}$ & 2.2447580000 & -1.0640030000 & 0.4388090000 \\
$\mathrm{H}$ & 0.9324550000 & -0.6688560000 & 1.5398420000 \\
$\mathrm{H}$ & 1.9181910000 & 1.0007560000 & -0.8102670000 \\
$\mathrm{H}$ & -1.3791510000 & -0.2382390000 & -1.5434970000 \\
$\mathrm{C}$ & 0.2332810000 & -1.2315610000 & -0.4329200000 \\
$\mathrm{H}$ & -0.1551550000 & -2.1776970000 & -0.0556800000 \\
$\mathrm{H}$ & 0.6940350000 & -1.4280180000 & -1.4036040000 \\
$\mathrm{C}$ & -1.7794450000 & -0.0115270000 & 0.6122880000 \\
$\mathrm{H}$ & -1.6760250000 & -0.7183930000 & 1.4311360000 \\
$\mathrm{H}$ & -0.9964710000 & 1.1292750000 & 0.8095870000 \\
$\mathrm{H}$ & -2.7928640000 & 0.3215460000 & 0.4162290000 \\
$\mathrm{C}$ & -0.1537670000 & 1.1658160000 & -0.2956270000 \\
$\mathrm{H}$ & 1.6734220000 & 1.5465470000 & 0.8428310000 \\
$\mathrm{H}$ & -0.4040650000 & 2.0421180000 & -0.8846790000
\end{tabular}

TS23:

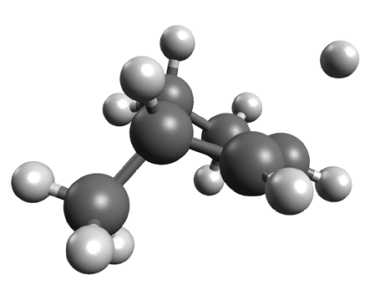

Frequencies:

561i, 122, 218, 248, 318, $359,375,493,683,747$, 792, 808, 878, 915, 956, 976, 994, 1005, 1063, 1101, 1123, 1137, 1207, 1239, 1313, 1326, 1338, $1358,1391,1415,1488$, $1500,1505,1508,1633$, 3039, 3042, 3051, 3071, $3105,3114,3118,3121$, 3198,3221
Geometry

\begin{tabular}{rrrr}
\hline $\mathrm{C}$ & -1.2793310000 & -0.7461690000 & -0.4668900000 \\
$\mathrm{C}$ & -1.2999640000 & 0.7522540000 & -0.3010190000 \\
$\mathrm{C}$ & 0.8062250000 & 0.0782570000 & 0.5314940000 \\
$\mathrm{H}$ & -2.2166350000 & -1.2226660000 & -0.1835860000 \\
$\mathrm{H}$ & -1.0970100000 & -0.9965540000 & -1.5161610000 \\
$\mathrm{H}$ & -2.4225830000 & 0.7942320000 & 1.4162040000 \\
$\mathrm{H}$ & 1.2095030000 & 0.1868490000 & 1.5409460000 \\
$\mathrm{C}$ & -0.1066990000 & -1.1642390000 & 0.4360560000 \\
$\mathrm{H}$ & 0.4244230000 & -2.0402830000 & 0.0652370000 \\
$\mathrm{H}$ & -0.4931070000 & -1.4047250000 & 1.4270000000 \\
$\mathrm{C}$ & 1.9799860000 & 0.0420590000 & -0.4514080000 \\
$\mathrm{H}$ & 2.6647460000 & -0.7703480000 & -0.2051490000 \\
$\mathrm{H}$ & 1.6228400000 & -0.1103540000 & -1.4715910000 \\
$\mathrm{H}$ & 2.5421280000 & 0.9764660000 & -0.4303280000 \\
$\mathrm{C}$ & -0.1449190000 & 1.1985550000 & 0.2064090000 \\
$\mathrm{H}$ & -2.0747000000 & 1.3821080000 & -0.7147240000 \\
$\mathrm{H}$ & 0.1086140000 & 2.2409770000 & 0.3442930000
\end{tabular}


TS24:

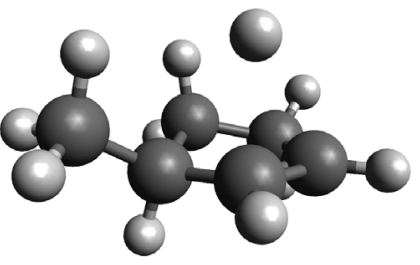

Frequencies:

526i, 143, 235, 241, 313, 364, 407, 523, 585, 754, 764, 835, 871, 923, 956, 975, 989, 1011, 1080, $1115,1127,1151,1214$, $1239,1309,1325,1340$, $1354,1402,1418,1485$, $1500,1502,1506,1631$, $3000,3027,3040,3055$, $3086,3114,3116,3119$, 3198,3221
Geometry

$\begin{array}{lrrr}\mathrm{C} & -1.6043440000 & -0.6403720000 & 0.0292830000 \\ \mathrm{C} & -1.3964030000 & 0.8471430000 & 0.0281000000 \\ \mathrm{C} & 0.7287330000 & -0.0615900000 & -0.4332790000 \\ \mathrm{H} & -2.2391720000 & -0.9809280000 & 0.8484090000 \\ \mathrm{H} & -2.0965870000 & -0.9515270000 & -0.8982760000 \\ \mathrm{H} & -2.1985550000 & 1.5600250000 & 0.1571370000 \\ \mathrm{C} & -0.1678840000 & -1.1840580000 & 0.1186330000 \\ \mathrm{H} & -0.0327850000 & -2.1288760000 & -0.4056610000 \\ \mathrm{H} & 0.0905520000 & -1.3453070000 & 1.1678380000 \\ \mathrm{C} & -0.1108710000 & 1.1656700000 & -0.1641350000 \\ \mathrm{H} & 0.2616950000 & 2.1711050000 & -0.3053110000 \\ \mathrm{H} & 0.3753610000 & 1.4808400000 & 1.8397900000 \\ \mathrm{C} & 2.1397960000 & -0.0458330000 & 0.1343460000 \\ \mathrm{H} & 2.6674530000 & -0.9672010000 & -0.1158780000 \\ \mathrm{H} & 2.7173740000 & 0.7895170000 & -0.2636030000 \\ \mathrm{H} & 2.1147040000 & 0.0506070000 & 1.2210860000 \\ \mathrm{H} & 0.8058030000 & -0.1640070000 & -1.5232180000\end{array}$

TS25:

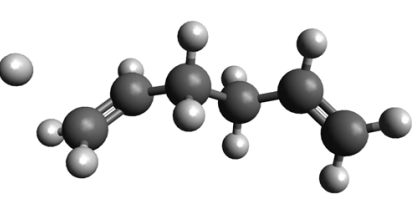

Frequencies:

540i, 66, 87, 102, 171, $251,304,375,430,449$, $652,703,791,944,960$, 966, 972, 979, 1030, 1045, 1048, 1101, 1189, 1255, $1280,1316,1329,1339$, $1376,1458,1462,1488$, 1500, 1679, 1736, 3028, $3035,3080,3098,3141$, 3147,3152 , 3155, 3237, 3244
Geometry

\begin{tabular}{rrrr}
\hline $\mathrm{C}$ & 1.8247860000 & -0.3279610000 & -0.2256810000 \\
$\mathrm{H}$ & 2.0027920000 & -1.1961040000 & -0.8538160000 \\
$\mathrm{C}$ & 0.4987540000 & -0.2705970000 & 0.4582030000 \\
$\mathrm{H}$ & 0.4321300000 & 0.6284450000 & 1.0734290000 \\
$\mathrm{H}$ & 0.4087670000 & -1.1258660000 & 1.1363190000 \\
$\mathrm{C}$ & -0.6742240000 & -0.3050480000 & -0.5325190000 \\
$\mathrm{H}$ & -0.5750300000 & -1.1955060000 & -1.1610780000 \\
$\mathrm{H}$ & -0.6176770000 & 0.5598950000 & -1.1959850000 \\
$\mathrm{C}$ & -1.9999650000 & -0.3333810000 & 0.1604810000 \\
$\mathrm{H}$ & -2.1730570000 & -1.1807580000 & 0.8185950000 \\
$\mathrm{C}$ & -2.9414670000 & 0.5890460000 & 0.0401850000 \\
$\mathrm{H}$ & -2.8074210000 & 1.4514280000 & -0.6024370000 \\
$\mathrm{H}$ & -3.8785710000 & 0.5147100000 & 0.5750850000 \\
$\mathrm{C}$ & 2.7899140000 & 0.5846980000 & -0.0984780000 \\
$\mathrm{H}$ & 3.7150870000 & 0.5081180000 & -0.6524990000 \\
$\mathrm{H}$ & 2.6337350000 & 1.4897230000 & 0.4756720000 \\
$\mathrm{H}$ & 3.8724500000 & -0.0746260000 & 1.5735750000
\end{tabular}


TS26:

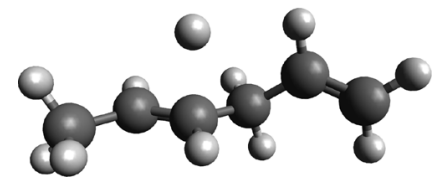

Frequencies: 630i, 61, 76, 157, 175, 261, 345, 381, 405, 450, 506, 677, 791, 897, 945, 958, 971, 1016, 1039, 1067, 1079, 1119, 1168, $1255,1300,1324,1331$, $1370,1420,1458,1479$, 1482, 1493, 1686, 1734, 3035, 3037, 3079, 3094, $3126,3145,3148,3155$, 3160,3236

Geometry

\begin{tabular}{rrrr}
\hline $\mathrm{C}$ & -1.7395010000 & 0.3633710000 & 0.1582930000 \\
$\mathrm{H}$ & -1.8102920000 & 1.2552740000 & 0.7742740000 \\
$\mathrm{C}$ & -0.5246380000 & -0.0592390000 & -0.2180600000 \\
$\mathrm{H}$ & -0.4478900000 & -0.9102360000 & -0.8884830000 \\
$\mathrm{H}$ & -0.3738020000 & -1.5073850000 & 1.1935890000 \\
$\mathrm{C}$ & 0.7474360000 & 0.7147280000 & 0.0090540000 \\
$\mathrm{H}$ & 0.5660920000 & 1.4824550000 & 0.7655210000 \\
$\mathrm{H}$ & 1.0042730000 & 1.2348400000 & -0.9183260000 \\
$\mathrm{C}$ & 1.9128160000 & -0.1352410000 & 0.4214330000 \\
$\mathrm{H}$ & 1.8123120000 & -0.6437690000 & 1.3750460000 \\
$\mathrm{C}$ & 3.0121430000 & -0.3048890000 & -0.2954520000 \\
$\mathrm{H}$ & 3.1423230000 & 0.1814940000 & -1.2554140000 \\
$\mathrm{H}$ & 3.8208720000 & -0.9339980000 & 0.0508630000 \\
$\mathrm{C}$ & -3.0157510000 & -0.3431230000 & -0.1478360000 \\
$\mathrm{H}$ & -3.7198120000 & 0.3201950000 & -0.6542390000 \\
$\mathrm{H}$ & -2.8478920000 & -1.2146080000 & -0.7795510000 \\
$\mathrm{H}$ & -3.5012170000 & -0.6779030000 & 0.7721310000
\end{tabular}

TS27:

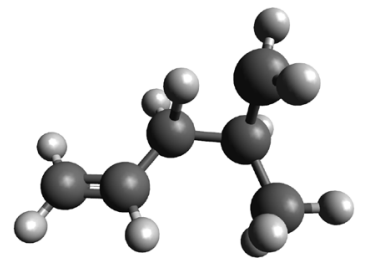

Frequencies:

2148i, 83, 112, 209, 289, $341,372,410,498,624$, 657, 826, 884, 911, 915, 929, 947, 1007, 1025, 1057, 1132, 1198, 1219, 1277, 1305, 1330, 1342, 1376, 1419, 1435, 1471, $1505,1510,1662,1796$, 3043, 3080, 3114, 3115, $3123,3131,3150,3171$, 3223,3243
Geometry

\begin{tabular}{rrrr}
\hline $\mathrm{C}$ & -0.3321180000 & -0.5409060000 & 0.3182710000 \\
$\mathrm{H}$ & -0.6199500000 & -1.2711570000 & 1.0705080000 \\
$\mathrm{H}$ & 0.2195700000 & -1.3416170000 & -0.6077650000 \\
$\mathrm{C}$ & 1.3892180000 & 1.3710310000 & -0.0048240000 \\
$\mathrm{H}$ & 1.1105580000 & 1.4924960000 & -1.0534260000 \\
$\mathrm{H}$ & 0.8397380000 & 2.1112070000 & 0.5775130000 \\
$\mathrm{H}$ & 2.4531720000 & 1.5933430000 & 0.0785910000 \\
$\mathrm{C}$ & -1.4208560000 & 0.2758780000 & -0.1953470000 \\
$\mathrm{H}$ & -1.1505550000 & 1.1637200000 & -0.7564870000 \\
$\mathrm{C}$ & -2.7173900000 & -0.0173800000 & -0.0624110000 \\
$\mathrm{H}$ & -3.0467890000 & -0.8908820000 & 0.4872940000 \\
$\mathrm{H}$ & -3.4824240000 & 0.6093920000 & -0.4986350000 \\
$\mathrm{C}$ & 1.1104100000 & -0.0406700000 & 0.4814690000 \\
$\mathrm{H}$ & 1.4590830000 & -0.1428450000 & 1.5086390000 \\
$\mathrm{C}$ & 1.6489750000 & -1.1275810000 & -0.4411800000 \\
$\mathrm{H}$ & 2.0865310000 & -0.8202590000 & -1.3854760000 \\
$\mathrm{H}$ & 2.0616400000 & -2.0256360000 & 0.0033720000
\end{tabular}


TS28:

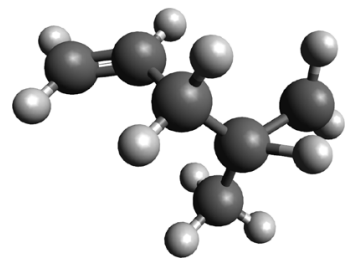

Frequencies:

1861i, 82, 87, 191, 209, $344,365,405,433,488$, $662,723,808,917,938$, $962,963,1022,1043$, 1057, 1104, 1223, 1243, $1311,1327,1342,1353$, 1423, 1436, 1460, 1480, 1491, 1498, 1728, 2225, 3005, 3030, 3079, 3082, $3117,3143,3155,3159$, 3234,3273
Geometry

$\begin{array}{rrrr}\mathrm{C} & -1.8353390000 & -0.9786130000 & -0.4087610000 \\ \mathrm{H} & -1.5336350000 & -2.0156290000 & -0.4090580000 \\ \mathrm{H} & -2.5907440000 & -0.6508380000 & -1.1070720000 \\ \mathrm{C} & 0.3415650000 & -0.4296850000 & 0.8231220000 \\ \mathrm{H} & 0.2212020000 & -1.4236710000 & 1.2649020000 \\ \mathrm{H} & 0.6751840000 & 0.2404370000 & 1.6184370000 \\ \mathrm{C} & -1.1368790000 & 1.4653110000 & -0.1245850000 \\ \mathrm{H} & -0.7329990000 & 2.1345100000 & 0.6359900000 \\ \mathrm{H} & -0.6072170000 & 1.6699810000 & -1.0626440000 \\ \mathrm{H} & -2.1858020000 & 1.7210000000 & -0.2808740000 \\ \mathrm{C} & 1.3861400000 & -0.4888470000 & -0.2559590000 \\ \mathrm{H} & 1.1646710000 & -1.1508760000 & -1.0879810000 \\ \mathrm{C} & 2.5011830000 & 0.2244410000 & -0.2723700000 \\ \mathrm{H} & 2.7496910000 & 0.9013410000 & 0.5370610000 \\ \mathrm{H} & 3.2059650000 & 0.1556740000 & -1.0901520000 \\ \mathrm{C} & -0.9803150000 & 0.0306340000 & 0.2692800000 \\ \mathrm{H} & -2.0244430000 & -0.5213720000 & 0.7970320000\end{array}$

TS29:

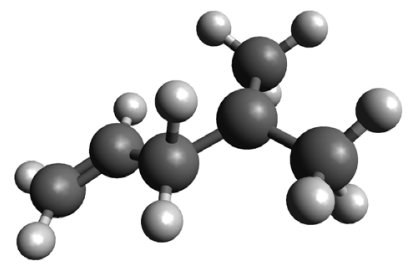

Frequencies:

1878i, 125, 160, 172, 205, 232, 347, 364, 407, 515, $610,793,819,871,949$, 977, 999, 1019, 1052, 1090, 1167, 1237, 1285, $1318,1330,1374,1417$, 1431, 1482, 1484, 1491, 1498, 1509, 1640, 2193, 2980, 2986, 3070, 3073, $3116,3119,3153,3165$, 3171,3249
Geometry

\begin{tabular}{rrrr}
\hline $\mathrm{C}$ & 0.3935980000 & -0.5249220000 & -0.1675080000 \\
$\mathrm{H}$ & -0.2321920000 & -0.3230450000 & -1.2386240000 \\
$\mathrm{H}$ & 0.4994690000 & -1.6000350000 & -0.0766850000 \\
$\mathrm{C}$ & -1.2526700000 & 1.4373400000 & 0.0323400000 \\
$\mathrm{H}$ & -1.0464420000 & 1.7430690000 & 1.0672880000 \\
$\mathrm{H}$ & -0.6153180000 & 2.0493820000 & -0.6084550000 \\
$\mathrm{H}$ & -2.2887340000 & 1.6897780000 & -0.1914250000 \\
$\mathrm{C}$ & 1.5747640000 & 0.2750170000 & 0.0138690000 \\
$\mathrm{H}$ & 1.4399480000 & 1.3498710000 & 0.0717500000 \\
$\mathrm{C}$ & 2.8238240000 & -0.2109090000 & 0.1104220000 \\
$\mathrm{H}$ & 3.0236640000 & -1.2743670000 & 0.0650250000 \\
$\mathrm{H}$ & 3.6699810000 & 0.4472440000 & 0.2430700000 \\
$\mathrm{C}$ & -1.0057380000 & -0.0218650000 & -0.1546510000 \\
$\mathrm{H}$ & -3.0528140000 & -0.6734320000 & -0.2349780000 \\
$\mathrm{C}$ & -2.0888200000 & -1.0025280000 & 0.1539780000 \\
$\mathrm{H}$ & -2.1954450000 & -1.1355080000 & 1.2389430000 \\
$\mathrm{H}$ & -1.8718670000 & -1.9857550000 & -0.2666050000
\end{tabular}


TS30:

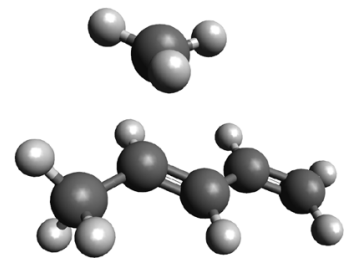

Frequencies:

455i, 91, 102, 145, 181, 207, 238, 289, 443, 468, 493, 513, 648, 778, 854, 918, 931, 966, 994, 1043, 1051, 1106, 1211, 1299, $1309,1335,1417,1421$, 1424, 1457, 1490, 1499, 1599, 1664, 3042, 3105, $3106,3133,3144,3150$, $3157,3164,3247,3267$, 3276
Geometry

$\begin{array}{lrrr}\mathrm{C} & 0.4226700000 & -0.5028930000 & 0.1826710000 \\ \mathrm{H} & 0.4932270000 & -0.9658990000 & 1.1628600000 \\ \mathrm{H} & -1.9503380000 & -1.3131230000 & 1.1534080000 \\ \mathrm{C} & -1.4750050000 & 1.7791760000 & 0.1982700000 \\ \mathrm{H} & -1.7058920000 & 1.5900270000 & 1.2362790000 \\ \mathrm{H} & -0.5750830000 & 2.3364120000 & -0.0145340000 \\ \mathrm{H} & -2.3065560000 & 1.8927880000 & -0.4832200000 \\ \mathrm{C} & 1.6332390000 & 0.0402390000 & -0.3769470000 \\ \mathrm{H} & 1.5454960000 & 0.5069150000 & -1.3541100000 \\ \mathrm{C} & 2.8290180000 & 0.0086320000 & 0.2180730000 \\ \mathrm{H} & 2.9601340000 & -0.4464930000 & 1.1922950000 \\ \mathrm{H} & 3.7055820000 & 0.4305420000 & -0.2525540000 \\ \mathrm{C} & -0.7937560000 & -0.4017500000 & -0.4111960000 \\ \mathrm{H} & -0.8296500000 & -0.0401150000 & -1.4330480000 \\ \mathrm{C} & -2.0050750000 & -1.1378390000 & 0.0790270000 \\ \mathrm{H} & -2.9245760000 & -0.5944920000 & -0.1321730000 \\ \mathrm{H} & -2.0788910000 & -2.1099500000 & -0.4145980000\end{array}$

TS31:

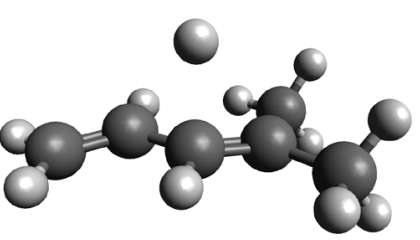

Frequencies:

715i, 86, 108, 147, 191, 227, 297, 357, 375, 444, $511,541,700,834,928$, $960,965,978,1012,1043$, 1088, 1100, 1175, 1251, $1337,1373,1421,1425$, $1458,1473,1485,1494$, 1500, 1648, 1723, 3029, $3035,3083,3087,3136$, 3152, 3156, 3157, 3189, 3246
Geometry

\begin{tabular}{rrrr}
\hline $\mathrm{C}$ & -0.3547570000 & -0.4846330000 & 0.0458930000 \\
$\mathrm{H}$ & -0.2967220000 & -0.8535700000 & 1.9691110000 \\
$\mathrm{H}$ & -0.5130390000 & -1.5526840000 & -0.0629160000 \\
$\mathrm{C}$ & 2.0597820000 & -0.9974040000 & -0.1096220000 \\
$\mathrm{H}$ & 2.7043150000 & -0.8758620000 & 0.7658890000 \\
$\mathrm{H}$ & 1.7206130000 & -2.0310730000 & -0.1411670000 \\
$\mathrm{H}$ & 2.6826970000 & -0.8081830000 & -0.9872120000 \\
$\mathrm{C}$ & -1.5712810000 & 0.3249410000 & 0.0214140000 \\
$\mathrm{H}$ & -1.4698010000 & 1.3974380000 & 0.1316140000 \\
$\mathrm{C}$ & -2.7871440000 & -0.1882600000 & -0.1309510000 \\
$\mathrm{H}$ & -2.9408110000 & -1.2557770000 & -0.2337120000 \\
$\mathrm{H}$ & -3.6657310000 & 0.4408620000 & -0.1528920000 \\
$\mathrm{C}$ & 0.9179080000 & -0.0325700000 & -0.0506260000 \\
$\mathrm{H}$ & 0.4695480000 & 2.0942020000 & -0.0337380000 \\
$\mathrm{C}$ & 1.3117740000 & 1.4092990000 & 0.0002130000 \\
$\mathrm{H}$ & 1.9784890000 & 1.6486490000 & -0.8311760000 \\
$\mathrm{H}$ & 1.8727560000 & 1.6077610000 & 0.9182690000
\end{tabular}


TS32:

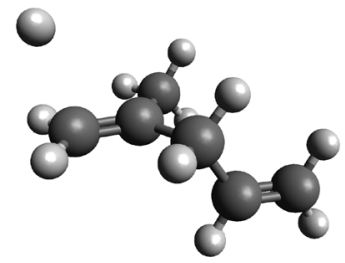

Frequencies:

443i, 54, 88, 162, 178, 220, 262, 372, 402, 471, 534, 661, 774, 857, 918, 953, 955, 971, 1003, 1033, 1052, 1070, 1137, 1241, 1309, 1331, 1338, 1418, 1450, 1460, 1478, 1487, 1502, 1691, 1733, 3036, 3039, 3090, 3097, 3140, $3146,3154,3159,3237$, 3240

Geometry

$\begin{array}{lrrr}\mathrm{C} & 0.2869820000 & -0.6611060000 & 0.5472150000 \\ \mathrm{H} & 0.0928800000 & -1.7286120000 & 0.6685940000 \\ \mathrm{H} & 0.5169770000 & -0.2549640000 & 1.5365080000 \\ \mathrm{C} & -0.9365270000 & 1.5060870000 & -0.0114310000 \\ \mathrm{H} & -0.8302510000 & 1.8954730000 & 1.0047210000 \\ \mathrm{H} & -0.0819980000 & 1.8769410000 & -0.5804530000 \\ \mathrm{H} & -1.8488830000 & 1.9137800000 & -0.4421450000 \\ \mathrm{C} & 1.4749480000 & -0.4696190000 & -0.3526590000 \\ \mathrm{H} & 1.3808540000 & -0.8931220000 & -1.3481170000 \\ \mathrm{C} & 2.5831200000 & 0.1735360000 & -0.0219100000 \\ \mathrm{H} & 2.7089460000 & 0.6129040000 & 0.9608040000 \\ \mathrm{H} & 3.4042830000 & 0.2795770000 & -0.7178460000 \\ \mathrm{C} & -0.9526070000 & 0.0096370000 & 0.0089280000 \\ \mathrm{H} & -2.8849430000 & -0.2199640000 & -0.8121480000 \\ \mathrm{C} & -2.0116720000 & -0.7000690000 & -0.3908020000 \\ \mathrm{H} & -3.1269780000 & -0.8507330000 & 1.4465360000 \\ \mathrm{H} & -1.9963500000 & -1.7820720000 & -0.3924900000\end{array}$

TS33:

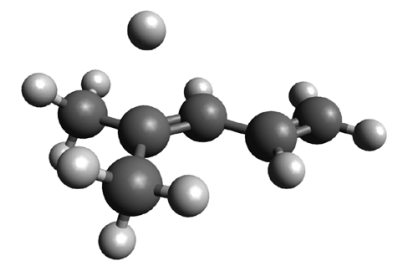

Frequencies:

660i, 119, 138, 185, 218, $238,354,370,418,450$, 484, 544, 678, 830, 901, 956, 967, 980, 1014, 1040, 1091, 1095, 1178, 1250, 1336, 1372, 1421, 1428, 1460, 1476, 1489, 1497, 1509, 1651, 1692, 3037, 3044, 3102, 3108, 3140, 3152 , 3155, 3158, 3185, 3247
Geometry

$\begin{array}{lrrr}\mathrm{C} & -0.3820740000 & -0.4971470000 & -0.0058790000 \\ \mathrm{H} & 0.8892030000 & -0.0805270000 & 2.0780550000 \\ \mathrm{H} & -0.5349700000 & -1.5720240000 & -0.0051580000 \\ \mathrm{C} & 1.2779260000 & 1.4007820000 & -0.0691400000 \\ \mathrm{H} & 1.5659430000 & 1.6301910000 & -1.0986910000 \\ \mathrm{H} & 0.4789090000 & 2.0784470000 & 0.2185080000 \\ \mathrm{H} & 2.1413640000 & 1.6100400000 & 0.5620420000 \\ \mathrm{C} & -1.5865830000 & 0.3037400000 & -0.0142260000 \\ \mathrm{H} & -1.4828040000 & 1.3820430000 & -0.0029630000 \\ \mathrm{C} & -2.8135580000 & -0.2168490000 & -0.0385100000 \\ \mathrm{H} & -2.9707720000 & -1.2886640000 & -0.0516420000 \\ \mathrm{H} & -3.6931930000 & 0.4110580000 & -0.0481250000 \\ \mathrm{C} & 0.8933410000 & -0.0488970000 & 0.0327410000 \\ \mathrm{H} & 2.8256310000 & -0.7944570000 & 0.6194890000 \\ \mathrm{C} & 2.0402080000 & -1.0113820000 & -0.1048610000 \\ \mathrm{H} & 2.4834940000 & -0.9139130000 & -1.0998990000 \\ \mathrm{H} & 1.7216350000 & -2.0436660000 & 0.0276320000\end{array}$


TS34:

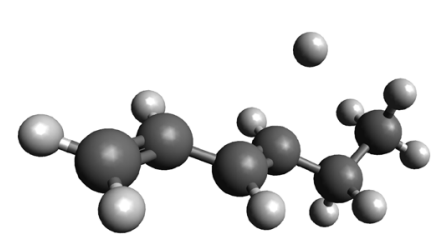

Frequencies:

556i, 65, 129, 165, 199, 260, 293, 382, 414, 447, 524, 663, 782, 890, 923, 954, 964, 992, 1051, 1056, 1100, 1133, 1217, 1276, $1307,1327,1339,1375$, 1420, 1463, 1482, 1501, 1506, 1661, 1705, 3028, $3048,3083,3121,3128$, $3142,3149,3154,3163$, 3247
Geometry

\begin{tabular}{rrrr}
\hline $\mathrm{C}$ & -3.1778180000 & -0.1168240000 & 0.1801730000 \\
$\mathrm{H}$ & -3.2713640000 & -1.0938250000 & 0.6387020000 \\
$\mathrm{H}$ & -4.0892420000 & 0.4394270000 & 0.0129600000 \\
$\mathrm{C}$ & -1.9892090000 & 0.3745950000 & -0.1635050000 \\
$\mathrm{H}$ & -1.9312180000 & 1.3583920000 & -0.6187550000 \\
$\mathrm{C}$ & -0.7340840000 & -0.3210470000 & 0.0331190000 \\
$\mathrm{H}$ & -0.7828830000 & -1.2982810000 & 0.5051430000 \\
$\mathrm{C}$ & 1.7583050000 & -0.5685940000 & -0.2202900000 \\
$\mathrm{H}$ & 1.9783580000 & -0.9606250000 & -1.2188280000 \\
$\mathrm{H}$ & 1.6342970000 & -1.4364660000 & 0.4297830000 \\
$\mathrm{C}$ & 2.9441020000 & 0.2726950000 & 0.2412670000 \\
$\mathrm{H}$ & 2.8014210000 & 0.6193680000 & 1.2647820000 \\
$\mathrm{H}$ & 3.8678250000 & -0.3039830000 & 0.1992080000 \\
$\mathrm{H}$ & 3.0683120000 & 1.1524040000 & -0.3920350000 \\
$\mathrm{C}$ & 0.4645010000 & 0.1821850000 & -0.3061870000 \\
$\mathrm{H}$ & 0.6328390000 & 1.4474360000 & 1.4142190000 \\
$\mathrm{H}$ & 0.4968700000 & 1.1381020000 & -0.8226330000
\end{tabular}

TS35:

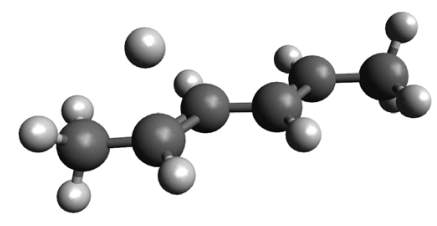

Frequencies:

559i, 100, 144, 153, 184, 209, 318, 331, 349, 364, 448, 554, 793, 887, 945, 946, 979, 1033, 1067, 1074, 1102, 1122, 1205, $1274,1327,1346,1367$, $1419,1423,1484,1485$, $1495,1500,1675,1732$, 3037, 3042, 3093, 3105, 3124, 3130, 3142, 3146, 3151,3158
Geometry

\begin{tabular}{rrrr}
\hline $\mathrm{C}$ & 0.6219900000 & -0.3045570000 & 0.0326900000 \\
$\mathrm{H}$ & 0.6820060000 & -1.3639210000 & 0.2669080000 \\
$\mathrm{C}$ & -0.7040240000 & 0.2649350000 & -0.0810700000 \\
$\mathrm{H}$ & -0.7624630000 & 1.3275110000 & -0.3017580000 \\
$\mathrm{C}$ & -1.8310050000 & -0.4303700000 & 0.0714030000 \\
$\mathrm{H}$ & -1.7582110000 & -1.4913000000 & 0.2947790000 \\
$\mathrm{C}$ & 3.1309420000 & -0.2038810000 & -0.0853010000 \\
$\mathrm{H}$ & 3.5533380000 & -0.2142900000 & -1.0928900000 \\
$\mathrm{H}$ & 3.8094920000 & 0.3736860000 & 0.5421720000 \\
$\mathrm{H}$ & 3.1107430000 & -1.2287250000 & 0.2838780000 \\
$\mathrm{C}$ & -3.2081140000 & 0.1327430000 & -0.0413930000 \\
$\mathrm{H}$ & -3.7731500000 & -0.3709710000 & -0.8288220000 \\
$\mathrm{H}$ & -3.7655370000 & -0.0110340000 & 0.8868010000 \\
$\mathrm{H}$ & -3.1864040000 & 1.1988870000 & -0.2649350000 \\
$\mathrm{C}$ & 1.7601260000 & 0.3954060000 & -0.1041780000 \\
$\mathrm{H}$ & 1.7798010000 & 1.2137550000 & 1.8499420000 \\
$\mathrm{H}$ & 1.6908960000 & 1.4407490000 & -0.3889880000
\end{tabular}


TS36:

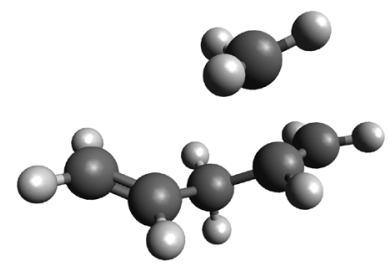

Frequencies:

510i, 67, 93, 128, 187, 250, 290, 420, 447, 527, $536,566,635,834,860$, 900, 929, 967, 987, 998, 1046, 1079, 1192, 1254, $1291,1313,1341,1419$, $1425,1444,1463,1478$, $1585,1739,3020,3085$, $3103,3140,3150,3152$, $3160,3237,3244,3264$, 3268

Polyatomic Products:

1,3-hexadiene:

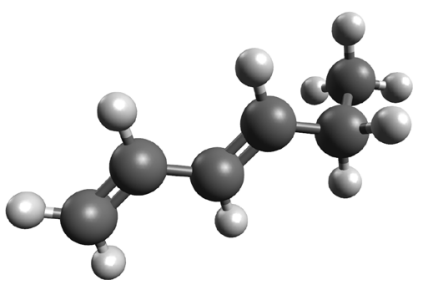

Frequencies:

68, 156, 173, 194, 263, $388,455,508,672,792$, 892, 922, 953, 961, 997, 1044, 1055, 1101, 1134, $1217,1276,1313,1336$, 1344, 1370, 1416, 1464, 1490, 1503, 1511, 1696, $1758,3036,3047,3083$, $3120,3127,3135,3143$, $3151,3160,3245$
Geometry

$\begin{array}{rrrr}\mathrm{C} & 0.2228180000 & -0.9513710000 & 0.1302150000 \\ \mathrm{H} & 0.2288480000 & -2.0124830000 & -0.1439100000 \\ \mathrm{H} & 0.2388250000 & -0.9130670000 & 1.2209900000 \\ \mathrm{C} & -0.7164020000 & 1.8416200000 & 0.0787220000 \\ \mathrm{H} & -1.6995070000 & 2.2508950000 & -0.1019260000 \\ \mathrm{H} & -0.4094120000 & 1.7536230000 & 1.1112190000 \\ \mathrm{H} & 0.0590690000 & 2.0905120000 & -0.6322830000 \\ \mathrm{C} & 1.4632530000 & -0.3265530000 & -0.4283800000 \\ \mathrm{H} & 1.4996810000 & -0.2364510000 & -1.5108970000 \\ \mathrm{C} & 2.4955690000 & 0.0905960000 & 0.2858660000 \\ \mathrm{H} & 2.4979560000 & 0.0231300000 & 1.3675220000 \\ \mathrm{H} & 3.3733930000 & 0.5145000000 & -0.1825080000 \\ \mathrm{C} & -1.0734600000 & -0.3693240000 & -0.3879800000 \\ \mathrm{H} & -1.0770260000 & -0.0801210000 & -1.4332590000 \\ \mathrm{C} & -2.2601180000 & -0.6204510000 & 0.2125650000 \\ \mathrm{H} & -3.1947890000 & -0.3391620000 & -0.2514440000 \\ \mathrm{H} & -2.3070050000 & -1.0384710000 & 1.2104510000\end{array}$

Geometry

$\begin{array}{lrrr}\mathrm{C} & 3.1098720000 & -0.1561450000 & 0.2681730000 \\ \mathrm{H} & 3.1725600000 & -1.2016060000 & 0.5453720000 \\ \mathrm{H} & 4.0306870000 & 0.4099100000 & 0.2665590000 \\ \mathrm{C} & 1.9485910000 & 0.4040060000 & -0.0557690000 \\ \mathrm{H} & 1.9225540000 & 1.4545710000 & -0.3288770000 \\ \mathrm{C} & 0.6746270000 & -0.2990390000 & -0.0733000000 \\ \mathrm{H} & 0.6947970000 & -1.3509990000 & 0.1993660000 \\ \mathrm{C} & -0.4842300000 & 0.2675040000 & -0.4003420000 \\ \mathrm{H} & -0.4907880000 & 1.3223660000 & -0.6665270000 \\ \mathrm{C} & -1.8101520000 & -0.4221710000 & -0.4161230000 \\ \mathrm{H} & -1.6778950000 & -1.4771150000 & -0.1690640000 \\ \mathrm{H} & -2.2205880000 & -0.3850290000 & -1.4294640000 \\ \mathrm{C} & -2.8113790000 & 0.2186070000 & 0.5458070000 \\ \mathrm{H} & -2.9626850000 & 1.2724130000 & 0.3070470000 \\ \mathrm{H} & -3.7793340000 & -0.2793910000 & 0.4912310000 \\ \mathrm{H} & -2.4532840000 & 0.1583070000 & 1.5736770000\end{array}$


1,4-hexadiene:

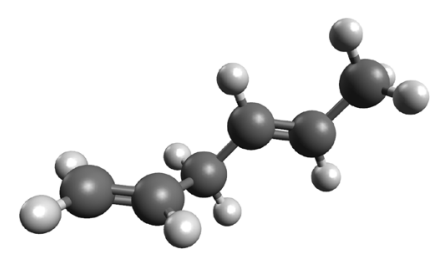

Frequencies:

73, 87, 178, 212, 282, 375, $398,515,674,800,894$, $945,958,969,1014,1045$, 1080, 1085, 1108, 1171, $1252,1307,1332,1344$, $1363,1422,1459,1482$, 1486, 1499, 1730, 1766, 3036, 3040, 3080, 3097, 3122, 3140, 3144, 3145, 3157,3236

1,5-hexadiene:

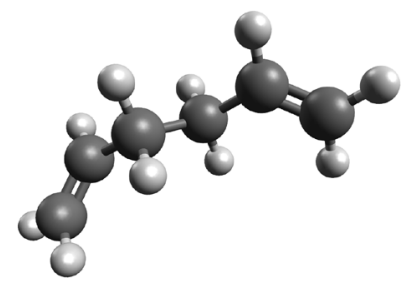

Frequencies:

73, 92, 109, 220, 355, 424, 446, 641, 674, 792, 944, 958, 964, 970, 973, 1043, 1047, 1049, 1102, 1190, 1255, 1282, 1319, 1335, 1341, 1378, 1460, 1463, 1489, 1501, 1734, 1737, 3029, 3034, 3078, 3096, 3141, 3141, 3152, 3152, 3236,3236
Geometry

\begin{tabular}{rrrr}
\hline $\mathrm{C}$ & 2.9624200000 & -0.4343690000 & -0.1140180000 \\
$\mathrm{H}$ & 3.2333760000 & -0.0346070000 & -1.0843800000 \\
$\mathrm{H}$ & 3.6780010000 & -1.0879590000 & 0.3663120000 \\
$\mathrm{C}$ & 1.8074990000 & -0.1325410000 & 0.4577510000 \\
$\mathrm{H}$ & 1.5660700000 & -0.5568680000 & 1.4277420000 \\
$\mathrm{C}$ & 0.7541730000 & 0.7545010000 & -0.1420410000 \\
$\mathrm{H}$ & 0.5679790000 & 1.6015650000 & 0.5234600000 \\
$\mathrm{H}$ & 1.1248800000 & 1.1599610000 & -1.0870920000 \\
$\mathrm{C}$ & -0.5346670000 & 0.0175850000 & -0.3722070000 \\
$\mathrm{H}$ & -0.4829030000 & -0.8207620000 & -1.0622950000 \\
$\mathrm{C}$ & -1.6892530000 & 0.3048810000 & 0.2109160000 \\
$\mathrm{H}$ & -1.7278380000 & 1.1415600000 & 0.9040920000 \\
$\mathrm{C}$ & -2.9708590000 & -0.4329900000 & -0.0082220000 \\
$\mathrm{H}$ & -3.3496930000 & -0.8451280000 & 0.9293000000 \\
$\mathrm{H}$ & -3.7440470000 & 0.2331840000 & -0.3964980000 \\
$\mathrm{H}$ & -2.8417000000 & -1.2533450000 & -0.7137230000
\end{tabular}

Geometry

\begin{tabular}{rrrr}
\hline $\mathrm{C}$ & -0.4416570000 & 2.8181460000 & 0.5939880000 \\
$\mathrm{H}$ & 0.1870670000 & 2.7547410000 & 1.4745240000 \\
$\mathrm{H}$ & -1.0820430000 & 3.6855640000 & 0.5078530000 \\
$\mathrm{C}$ & -0.4219260000 & 1.8760540000 & -0.3355860000 \\
$\mathrm{H}$ & -1.0712870000 & 1.9767460000 & -1.2013240000 \\
$\mathrm{C}$ & 0.4219260000 & 0.6414050000 & -0.2928910000 \\
$\mathrm{H}$ & 1.0832340000 & 0.6248780000 & -1.1649280000 \\
$\mathrm{H}$ & 1.0625840000 & 0.6558820000 & 0.5908110000 \\
$\mathrm{C}$ & -0.4219260000 & -0.6414050000 & -0.2928910000 \\
$\mathrm{H}$ & -1.0832340000 & -0.6248780000 & -1.1649280000 \\
$\mathrm{H}$ & -1.0625840000 & -0.6558820000 & 0.5908110000 \\
$\mathrm{C}$ & 0.4219260000 & -1.8760540000 & -0.3355860000 \\
$\mathrm{H}$ & 1.0712870000 & -1.9767460000 & -1.2013240000 \\
$\mathrm{C}$ & 0.4416570000 & -2.8181460000 & 0.5939880000 \\
$\mathrm{H}$ & -0.1870670000 & -2.7547410000 & 1.4745240000 \\
$\mathrm{H}$ & 1.0820430000 & -3.6855640000 & 0.5078530000
\end{tabular}


2,4-hexadiene:

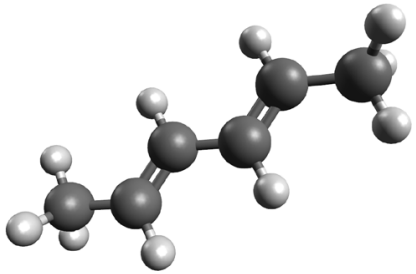

Frequencies: 102, 145, 169, 194, 244, $342,344,440,555,783$, $885,944,948,983,1036$, 1075, 1077, 1103, 1121, $1203,1276,1337,1350$, $1368,1418,1423,1484$, $1484,1495,1500,1723$, 1769, 3036, 3037, 3092, 3092, 3121, 3121, 3138, $3142,3147,3150$

3-methylcyclopentene:

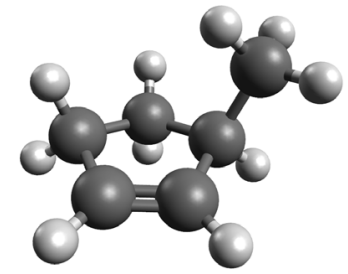

Frequencies:

107, 251, 273, 356, 487, $691,727,778,807,873$, 915, 960, 977, 996, 1010, 1067, 1109, 1128, 1141, $1210,1244,1310,1325$, $1339,1360,1393,1414$, 1490, 1500, 1505, 1512, 1710, 3037, 3039, 3049, $3070,3086,3112$, 3115, $3118,3190,3217$
Geometry

$\begin{array}{lrrr}\mathrm{C} & -1.7907280000 & -0.4294360000 & -0.0000030000 \\ \mathrm{H} & -1.7138790000 & -1.5134620000 & -0.0000010000 \\ \mathrm{C} & -0.6685990000 & 0.2860870000 & -0.0000020000 \\ \mathrm{H} & -0.7329250000 & 1.3713240000 & -0.0000030000 \\ \mathrm{C} & 0.6685990000 & -0.2860870000 & 0.0000020000 \\ \mathrm{H} & 0.7329250000 & -1.3713240000 & 0.0000030000 \\ \mathrm{C} & 1.7907280000 & 0.4294360000 & 0.0000030000 \\ \mathrm{H} & 1.7138790000 & 1.5134620000 & 0.0000010000 \\ \mathrm{C} & -3.1712760000 & 0.1392000000 & -0.0000060000 \\ \mathrm{H} & -3.7319520000 & -0.1928290000 & -0.8766310000 \\ \mathrm{H} & -3.7319550000 & -0.1928260000 & 0.8766180000 \\ \mathrm{H} & -3.1532100000 & 1.2287930000 & -0.0000080000 \\ \mathrm{C} & 3.1712760000 & -0.1392000000 & 0.0000060000 \\ \mathrm{H} & 3.7319550000 & 0.1928260000 & -0.8766180000 \\ \mathrm{H} & 3.7319520000 & 0.1928290000 & 0.8766310000 \\ \mathrm{H} & 3.1532100000 & -1.2287930000 & 0.0000080000\end{array}$

Geometry

\begin{tabular}{rrrr}
\hline $\mathrm{C}$ & 1.4187270000 & -0.6232910000 & 0.3691930000 \\
$\mathrm{C}$ & 1.2976600000 & 0.8640580000 & 0.1753070000 \\
$\mathrm{C}$ & 0.1164590000 & 1.2055270000 & -0.3179900000 \\
$\mathrm{C}$ & -0.7895550000 & 0.0160980000 & -0.5176590000 \\
$\mathrm{H}$ & 2.3568660000 & -1.0241220000 & -0.0167270000 \\
$\mathrm{H}$ & 1.3892920000 & -0.8723000000 & 1.4341140000 \\
$\mathrm{H}$ & 2.0807820000 & 1.5586030000 & 0.4475030000 \\
$\mathrm{H}$ & -0.2085630000 & 2.2206970000 & -0.5048170000 \\
$\mathrm{H}$ & -1.2464180000 & 0.0325600000 & -1.5096980000 \\
$\mathrm{C}$ & 0.1936670000 & -1.1699180000 & -0.3903920000 \\
$\mathrm{H}$ & -0.2606100000 & -2.0278150000 & 0.1047770000 \\
$\mathrm{H}$ & 0.5027460000 & -1.4933210000 & -1.3845070000 \\
$\mathrm{C}$ & -1.9097500000 & -0.0140820000 & 0.5241440000 \\
$\mathrm{H}$ & -2.5225590000 & 0.8869320000 & 0.4719160000 \\
$\mathrm{H}$ & -2.5616040000 & -0.8752110000 & 0.3704690000 \\
$\mathrm{H}$ & -1.4931720000 & -0.0763770000 & 1.5313520000
\end{tabular}


4-methyl-1,3-pentadiene:

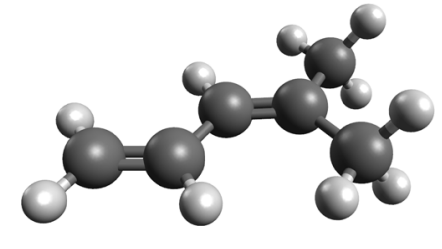

Frequencies:

107, 127, 177, 211, 247, 367, 446 459, 533, 687, $834,905,955,966,980$, 1013, 1044, 1093, 1110, 1176, 1251, 1334, 1375, 1422, 1429, 1464, 1476, 1490, 1497, 1503, 1691, 1757, 3031, 3039, 3084, $3089,3133,3146,3151$, 3154, 3181, 3244

2-methyl-1,4-pentadiene:

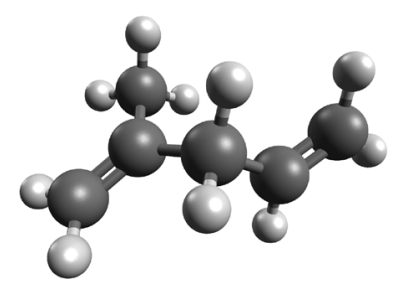

Frequencies:

$61,89,184,233,372,401$, $471,521,657,731,855$, 918, 945, 953, 969, 1001, 1035, 1053, 1075, 1141, $1243,1308,1329,1338$, $1419,1455,1461,1480$, $1488,1503,1729,1746$, 3038, 3041, 3089, 3098, $3137,3145,3149,3157$, 3232,3236
Geometry

$\begin{array}{rrrr}\mathrm{C} & -2.0547130000 & -1.0147570000 & -0.0000030000 \\ \mathrm{H} & -2.6885670000 & -0.8574080000 & -0.8765660000 \\ \mathrm{H} & -2.6885590000 & -0.8574220000 & 0.8765690000 \\ \mathrm{C} & -0.9035720000 & -0.0523600000 & 0.0000000000 \\ \mathrm{C} & 0.3580960000 & -0.4941820000 & -0.0000010000 \\ \mathrm{H} & 0.5156960000 & -1.5689650000 & -0.0000040000 \\ \mathrm{H} & -1.7200780000 & -2.0506420000 & -0.0000130000 \\ \mathrm{C} & -1.3064910000 & 1.3923570000 & 0.0000030000 \\ \mathrm{H} & -0.4656210000 & 2.0800570000 & 0.0000190000 \\ \mathrm{H} & -1.9220550000 & 1.6104180000 & -0.8761510000 \\ \mathrm{H} & -1.9220800000 & 1.6104080000 & 0.8761420000 \\ \mathrm{C} & 1.5732810000 & 0.3055000000 & 0.0000020000 \\ \mathrm{H} & 1.4736410000 & 1.3844790000 & 0.0000060000 \\ \mathrm{C} & 2.7975900000 & -0.2156110000 & -0.0000010000 \\ \mathrm{H} & 2.9542290000 & -1.2877710000 & -0.0000060000 \\ \mathrm{H} & 3.6782490000 & 0.4111680000 & 0.0000010000\end{array}$

Geometry

$\begin{array}{lrrr}\mathrm{C} & -2.0585670000 & -0.7954300000 & -0.2513910000 \\ \mathrm{H} & -2.0227040000 & -1.8742020000 & -0.1661870000 \\ \mathrm{H} & -2.9765110000 & -0.3610250000 & -0.6263730000 \\ \mathrm{C} & -1.0240790000 & -0.0389740000 & 0.0920590000 \\ \mathrm{C} & 0.2630110000 & -0.6422900000 & 0.6054320000 \\ \mathrm{H} & 0.1115260000 & -1.7088870000 & 0.7835660000 \\ \mathrm{H} & 0.5247280000 & -0.1831950000 & 1.5629400000 \\ \mathrm{C} & -1.0479380000 & 1.4570880000 & -0.0096290000 \\ \mathrm{H} & -0.8827230000 & 1.9082480000 & 0.9719670000 \\ \mathrm{H} & -0.2449890000 & 1.8136260000 & -0.6575490000 \\ \mathrm{H} & -1.9975720000 & 1.8183360000 & -0.3998300000 \\ \mathrm{C} & 1.4019350000 & -0.4573910000 & -0.3563930000 \\ \mathrm{H} & 1.2709330000 & -0.9212690000 & -1.3295660000 \\ \mathrm{C} & 2.5082350000 & 0.2239140000 & -0.1048440000 \\ \mathrm{H} & 2.6693640000 & 0.7047900000 & 0.8530280000 \\ \mathrm{H} & 3.2923740000 & 0.3220760000 & -0.8433950000\end{array}$


Cyclopentene:

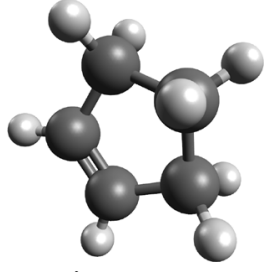

Frequencies:

147, 398, 618, 723, 790, $832,903,920,928,986$, 994, 1053, 1078, 1135, $1167,1238,1243,1319$, 1334, 1342, 1392, 1490, 1497, 1518, 1709, 3034, 3035, 3068, 3086, 3091, $3125,3195,3221$

1,4-pentadiene:

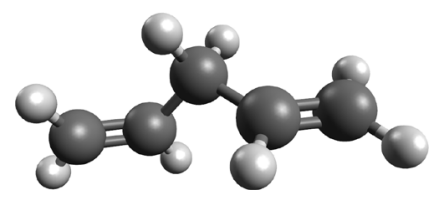

Frequencies:

85, 100, 304, 381, 463, 623, 691, 907, 926, 969, 971, 979, 1042, 1048, 1097, 1182, 1273, 1313, $1332,1340,1457,1463$, 1484, 1725, 1739, 3039, 3084, 3146, 3146, 3159, $3159,3237,3237$

Methyl:

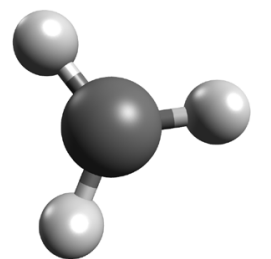

Frequencies:

528, 1409, 1410, 3122, 3303,3303
Geometry

$\begin{array}{rrrr}\mathrm{C} & -0.2667570000 & -1.1977950000 & 0.0000000000 \\ \mathrm{C} & 0.0687450000 & -0.3269130000 & 1.2276530000 \\ \mathrm{C} & 0.0687450000 & 1.0682540000 & -0.6625740000 \\ \mathrm{H} & 0.2649240000 & -2.1475950000 & 0.0000000000 \\ \mathrm{H} & -1.3338450000 & -1.4217870000 & 0.0000000000 \\ \mathrm{H} & 1.0530970000 & -0.5677540000 & 1.6409340000 \\ \mathrm{H} & 0.1061580000 & 1.9539880000 & -1.2818930000 \\ \mathrm{C} & 0.0687450000 & -0.3269130000 & -1.2276530000 \\ \mathrm{H} & -0.6494610000 & -0.4562010000 & -2.0383180000 \\ \mathrm{H} & 1.0530970000 & -0.5677540000 & -1.6409340000 \\ \mathrm{C} & 0.0687450000 & 1.0682540000 & 0.6625740000 \\ \mathrm{H} & -0.6494610000 & -0.4562010000 & 2.0383180000 \\ \mathrm{H} & 0.1061580000 & 1.9539880000 & 1.2818930000 \\ \mathrm{C} & -0.2667570000 & -1.1977950000 & 0.0000000000\end{array}$

Geometry

\begin{tabular}{rrrr}
\hline $\mathrm{C}$ & 0.0000000000 & 2.3582730000 & -0.1824440000 \\
$\mathrm{H}$ & -0.8384300000 & 2.6271060000 & 0.4495880000 \\
$\mathrm{H}$ & 0.4053820000 & 3.1334380000 & -0.8185460000 \\
$\mathrm{C}$ & 0.5069910000 & 1.1358430000 & -0.1728900000 \\
$\mathrm{H}$ & 1.3434320000 & 0.9001500000 & -0.8237870000 \\
$\mathrm{C}$ & 0.0000000000 & 0.0000000000 & 0.6694360000 \\
$\mathrm{H}$ & 0.8019900000 & -0.3644220000 & 1.3164400000 \\
$\mathrm{H}$ & -0.8019900000 & 0.3644220000 & 1.3164400000 \\
$\mathrm{C}$ & -0.5069910000 & -1.1358430000 & -0.1728900000 \\
$\mathrm{H}$ & -1.3434320000 & -0.9001500000 & -0.8237870000 \\
$\mathrm{C}$ & 0.0000000000 & -2.3582730000 & -0.1824440000 \\
$\mathrm{H}$ & 0.8384300000 & -2.6271060000 & 0.4495880000 \\
$\mathrm{H}$ & -0.4053820000 & -3.1334380000 & -0.8185460000 \\
$\mathrm{C}$ & 0.0000000000 & 2.3582730000 & -0.1824440000
\end{tabular}

Geometry

\begin{tabular}{rrrr}
\hline $\mathrm{C}$ & 0.0000080000 & -0.0000120000 & 0.0000000000 \\
$\mathrm{H}$ & -0.2031130000 & 1.0589480000 & -0.0000010000 \\
$\mathrm{H}$ & -0.8155910000 & -0.7053130000 & -0.0000010000 \\
$\mathrm{H}$ & 1.0186590000 & -0.3535640000 & -0.0000010000
\end{tabular}

\section{References}

1. Gong, C. M.; Li, Z. R.; Li, X. Y., Theoretical kinetic study of thermal decomposition of cyclohexane. Energ. Fuel 2012, 26, 2811-2820. 